\title{
DOES HEALTH INSURANCE COVERAGE LEAD TO BETTER HEALTH AND EDUCATIONAL OUTCOMES? EVIDENCE FROM RURAL CHINA
}

\author{
Yuyu Chen \\ Ginger Zhe Jin \\ Working Paper 16417 \\ http://www.nber.org/papers/w16417
NATIONAL BUREAU OF ECONOMIC RESEARCH
1050 Massachusetts Avenue
Cambridge, MA 02138
September 2010

This project is a collaborative effort with a local government of China. The views expressed herein are those of the authors and do not necessarily reflect the views of the National Bureau of Economic Research.

NBER working papers are circulated for discussion and comment purposes. They have not been peerreviewed or been subject to the review by the NBER Board of Directors that accompanies official NBER publications.

(C) 2010 by Yuyu Chen and Ginger Zhe Jin. All rights reserved. Short sections of text, not to exceed two paragraphs, may be quoted without explicit permission provided that full credit, including (C) notice, is given to the source. 
Does Health Insurance Coverage Lead to Better Health and Educational Outcomes? Evidence from Rural China

Yuyu Chen and Ginger Zhe Jin

NBER Working Paper No. 16417

September 2010, Revised March 2012

JEL No. I18,I21,I38

\begin{abstract}
Using 2006 China Agricultural Census (CAC), we examine whether the introduction of the New Cooperative Medical System (NCMS) has affected child mortality, maternal mortality, and school enrollment of the 6-16 years olds. Our data cover 5.9 million people living in eight low-income rural counties, of which four adopted the NCMS by 2006 and four did not adopt it until 2007.

Raw data suggest that enrolling in NCMS is associated with better school enrollment and lower mortality of young children and pregnant women. However, using a difference-in-difference propensity score method, we find most of these differences are driven by the endogenous introduction and take-up of NCMS, and out method overcomes classical propensity score matching's failure to address the selection bias. While the NCMS does not affect child mortality and maternal mortality, it does help improve the school enrollment of six-year-olds.
\end{abstract}

Yuyu Chen

Applied Economics Department

Guanghua School of Management

Peking University

Beijing, 100871

Chenyuyu@gsm.pku.edu.cn

Ginger Zhe Jin

University of Maryland

Department of Economics

3105 Tydings Hall

College Park, MD 20742-7211

and NBER

jin@econ.umd.edu 


\section{Introduction}

Many governments advocate nationwide health insurance in order to improve individual welfare. In this paper, we use the recent expansion of health insurance coverage in rural China to quantify the impact of health insurance on child mortality, maternal mortality, and school enrollment. Although the Chinese economy has continued to grow during the past 20 years, many rural residents remain poor and have difficulty obtaining access to health care when they are sick. ${ }^{2}$ To address the problems associated with the lack of health insurance in rural $\operatorname{areas}^{3}$, China initiated the National Cooperative Medical System (NCMS) in 2003, targeting rural residents with large subsidies from central and local governments. Unlike mandatory insurance proposed elsewhere, the NCMS is implemented county-by-county, allowing local governments to decide when to introduce the NCMS, how much premium to charge, and how many benefits to offer. If the county offers the NCMS, a rural household can choose to enroll in the NCMS for either every household member or none of them. Diffusion of the NCMS has been fast: in 2004, $14 \%$ of counties offered NCMS coverage (MOH 2005); by June 30, 2008, all counties offered the NCMS, covering 91.54\% of the rural population. ${ }^{4}$ A more detailed description of the NCMS can be found in Wagstaff et al. (2009).

2 China shows an uneven progress against poverty (Ravallion and Chen 2007). In 2005, China still has 208 million people living below the World Bank's \$1.25-per-day poverty line (Chen and Ravallion 2008), most of them being rural. According to the 2007 National Statistical Yearbook, rural residents on average spend 5.34\% of income on health care and the ratio increases to $10 \%$ for the poorest twenty percent. These numbers tend to underestimate the financial burden of health care cost because poor households are often under-treated. There is also a sizable health-expenditure disparity between urban and rural areas, largely due to the increasing gaps in income, health care utilization and local government budget deficit (Liu et al. 1999; Chou and Wang 2009).

3 The old community-based health insurance system broke down when the rural economy shifted away from the collective system in 1978 (Hsiao 1984). As a result, patients face increased financial burden, reduced access to health care services, and compromised service quality (MOH 1999).

${ }^{4}$ News release from Guang Ming Daily, written by Ying Zhang, October 22, 2008, accessed at http://www.hyey.com/Article/zhengcezhuanti/xinnonghe/now/xiyue/200810/141630.html on June 5, 2010. This article cites data source from the Ministry of Health. 
In theory, health insurance can affect a household in many ways, ranging from increased health care utilization, better health, and higher productivity, to greater financial resources freed up from medical costs. Our data do not include direct measures of health care utilization, but they allow us to study the effect of the NCMS on mortality of pregnant women and young children at the village level and school enrollment at the individual level.

Mortality and educational outcomes have long been studied as potential consequences of health insurance. For example, the expansion of Medicaid coverage in the US has been shown to improve the mother's prenatal care, reduce infant mortality, and reduce the incidence of low birth weight (Currie and Gruber 1996a, 1996b); the introduction of the State Children's Health Insurance Program (SCHIP) has been linked to better child health and better school performance (Joyce and Racine 2003; Levine and Schanzenbach 2009); and the adoption of nationwide health insurance has reduced the mortality rate of young children in Taiwan (Chou 2011). There is also evidence that health insurance can relieve financial burdens on individual households (Miller et al. 2010), and an increase in financial resources available can boost children's school performance (Morris, Duncan \& Rodrigues 2004; Dahl and Lochner 2005). Several survey articles have reviewed research on the impact of health insurance on health (Levy and Meltzer 2008) and the impact of child health on educational outcomes in both developed and developing countries (Currie 2009; Glewwe and Miguel 2008).

Turning to the effects of the NCMS in particular, the existing evidence is mixed. On the positive side, some studies show that the NCMS reduced illness-related poverty, increased inpatient/outpatient utilization of health services and reduced the rate of non-hospitalization after two 
weeks of diagnosis (Chen et al. 2005; Yuan et al. 2006; Wagstaff et al. 2009; Wang 2007; Zhu et al. 2007; Fang et al. 2006; Zhang et al. 2007). Because deliveries constitute a significant fraction of hospitalizations, many studies compare the percent of hospitalized deliveries before and after the NCMS. Cheng et al. (2008) report an increase in the hospitalized delivery rate from $85 \%$ to $96.9 \%$ in 14 counties of Hubei (2002-2006), from $77.5 \%$ to $92.5 \%$ in 3 counties of Chongqing (2003-2007), and from $32.43 \%$ to $83.24 \%$ in the rural area of Qinghai (2002-2007). ${ }^{5}$ Similar increases have been shown in Guangxi (Liao 2009) and Yunnan (Lu and Li 2010). These studies find that the NCMS increased the health of women and infants because mortality risk is much lower for hospital delivery than for home delivery. ${ }^{6}$ Two of them also report a significant decline in maternal and birth deaths after the NCMS (Liao 2009; Lu and Li 2010). On the negative side, some researchers have expressed concerns that the low reimbursement rate in the NCMS will limit its effectiveness (Zhang et al. 2006, Yi et al. 2009), and that the China Health and Nutrition Survey lacks evidence of better health care utilization and improved health condition after the adoption of the NCMS (Lei and Lin 2009).

This paper aims to provide additional evidence regarding the impact of the NCMS, using a large cross-sectional data set from the 2006 China Agriculture Census. Unlike Wagstaff et al. (2009), we do not track individuals before and after the introduction of the NCMS. But our data cover neighboring areas within a poor inland province including four counties that introduced the NCMS at the time of the survey (end of 2006) and four counties that did not introduce the NCMS until 2007.

\footnotetext{
5 Focusing on one county of Qinghai, Shi (2008) shows that the rate of hospitalized delivery increased from $90.16 \%$ in 2004 to $98.67 \%$ in 2006.

6 According to WHO (2005), most maternal deaths take place in developing countries and the leading causes are haemorrhage (severe bleeding, 25\%), infections (15\%), and eclampsia (12\%). Skilled professional care is essential to save lives at and after birth.
} 
The eight counties are geographically adjacent to each other, belong to the same administrative district, and are similar in demographics, access to health care services, and access to public education. Because the data were collected as a part of the census, our sample includes 5.9 million individuals, 1.4 million households, and 1.4 million school age children across 3,977 villages. ${ }^{7}$ The $^{2}$ advantage of such a large sample is that it helps capture severe health risks that are small probability events and could have a catastrophic impact on a rural household without health insurance.

Furthermore, the high poverty in this area makes it attractive for identifying the impact of the NCMS on a financially vulnerable population.

It is difficult to establish a causal relationship between health insurance and measurable outcomes in observational data because they both may be influenced by unobservable factors. There are two sets of endogenous unobservables that may contaminate the estimation. One is heterogeneous county-level characteristics. For instance, if the NCMS counties are richer and in better fiscal condition, then the population in the NCMS counties could have better health and educational outcomes compared with the population in the non-NCMS counties even without the NCMS. The other set is heterogeneous household-level characteristics. For example, comparing two households residing in the same NCMS county, richer and more health-conscious households may be more likely to take up the insurance.

The classical cross-sectional propensity score matching method focuses on estimating the effect of a treatment program (i.e. the NCMS counties in our context) by comparing the treated individual with an untreated one. The validity of the method relies on the assumption that treated and

${ }^{7}$ There are actually 3,986 villages in the data but 9 did not provide any village-level information. We deleted them from analysis. 
untreated individuals are similar in unobservables if they are matched on observables (Rosenbaum and Rubin, 1983). To correct the two kinds of selection bias mentioned above, instead of directly estimating the treatment effect of enrolling in the NCMS, we estimate the treatment effect of the NCMS being offered in a county. This is an intent-to-treat analysis.

Specifically, we propose a difference-in-difference (DID) propensity score method using both NCMS and non-NCMS county data, with which we can explore within-county heterogeneity and cross-county difference. The key assumption in classical cross section matching, that individuals matched in observables are similar in the unobservables, can be relaxed when we construct the propensity score to use households in the non-NCMS counties as a control for similar households in the NCMS counties, regardless of the participation status of the households. The heterogeneity within a county allows us to control for the unobservable county specific attributes and thus account for the endogenous introduction of the NCMS county by county. Our method is similar to the DID matching strategy proposed by Heckman, Ichimura and Todd (1997) and Heckman, Ichimura, Smith and Todd (1998). The main difference is that they use longitudinal (or repeated cross-section) data to difference out the time-invariant factors before and after a treatment program ${ }^{8}$, whereas we use all households within each county with unequal propensity to enroll in the NCMS to difference out the county-specific unobservables and use households in non-NCMS counties as a control group.

\footnotetext{
8 Using longitudinal data that track program participants and non-participants before and after a treatment program, Smith and Todd (2005) show that DID matching estimators perform much better than classical cross-sectional matching when participants and non-participants are drawn from different regional labor markets and/or were given different survey questionnaires.
} 
Wagstaff et al. (2009) also use DID together with the propensity score method to evaluate the impact of the NCMS (on health care utilization), but there is an important difference between their methodology and ours: they compare the NCMS-insured individuals with observationally similar individuals in non-NCMS counties, while we compare both the NCMS insured and uninsured individuals in the NCMS counties with individuals in the non-NCMS counties. As detailed below, the two types of comparisons lead to different results and we argue that our method can better address the endogenous take-up of NCMS due to non-observables.

Results from our DID propensity score method suggest that most of the seemingly beneficial effects of NCMS are driven by selection. By applying the DID propensity score method to populations of different socioeconomic status, we find that the NCMS may have moderate effects in improving the school enrollment of six-year-olds.

The rest of the paper is organized as follows: Section 2 describes the data and the background of NCMS in the studied area. Section 3 presents a data summary and classical analysis (OLS and propensity score matching) of key outcomes. Section 4 specifies our DID propensity score methodology. Section 5 reports the main results. Section 6 offers a brief discussion and conclusion.

\section{Background and Data}

The National Bureau of Statistics of China organized local governments to conduct two rounds of the China Agricultural Census (CAC) in 1996 and 2006. Drawing from the 2006 CAC, our data cover all the residents residing or having a registered residence in a continuous area as of December 31, 2006. Due to data confidentiality, we are not allowed to reveal the geographic 
location, but we can say that the studied counties are mostly rural, belong to the same inland province, and have a per-capita income below the national average. In total, we observe 5.9 million individuals in 1.4 million households in 3,977 villages. The villages spread across 250 townships in 8 counties, among which one county adopted the NCMS in 2004 (referred to as county A), three counties adopted it in 2006 (B, C, D), and the other four did not adopt the NCMS until 2007 (E, F, G, $\mathrm{H})$. The size of the whole census area is roughly $16,000 \mathrm{~km}^{2}$ in total, with an average area of $4 \mathrm{~km}^{2}$ per village. More details of this data set are available in Chen, Jin and Yue (2010).

In 2006, each NCMS participating individual cost on average $50 \mathrm{RMB}^{9}$ in the $\mathrm{NCMS}$ system, of which 10 RMB was paid by the individual, 20 RMB was subsidized by the central government and the other $20 \mathrm{RMB}$ were contributed by the county government. This structure remained unchanged in 2007 and $2008^{10}$, but both the central and local government subsidies increased from 20 to $40 \mathrm{RMB}$ per person in 2009. To ensure the appropriate use of the NCMS funds, the central government required local governments to devote the funds to reimbursement and fund management. Local governments were also required to post a list of existing claims and reimbursements within each village, so that both participating and non-participating villagers had a good idea of how much reimbursement they could obtain from the NCMS if they participated.

In the study area, the NCMS paid the insured amount directly if the treatment was delivered at a county- or town-level hospital. If health services were delivered at an above-county hospital, the

\footnotetext{
9 The exchange rate between the Chinese currency (RMB) and US dollar at the study period was roughly seven RMB for one dollar.

10 One exception is that that the individual premium of county E was 12 instead of 10 RMB in 2007. County E reduced this number to $10 \mathrm{RMB}$ in 2008.
} 
NCMS required the patient to pay the full amount out of pocket and then seek reimbursement. For simplicity, we refer to both types of NCMS payment as reimbursement. In our sample period, the reimbursement rate was $60-70 \%$ for township healthcare providers, $45-55 \%$ for county level providers, and $35-40 \%$ for out-of-county providers. These rates have increased $5-15 \%$ over time because the total subsidy from the central and local governments doubled in 2009. Benefits cover both inpatient and outpatient care performed by designated providers for designated procedures, so the actual reimbursement rate for all diseases could be significantly lower than the percentages mentioned above. Moreover, the reimbursement is capped at 200-300 RMB per individual per year for outpatient care and 10k-25k RMB for inpatient care. As documented in the existing literature, the potential benefit of the NCMS in relieving a household's financial burden mostly depends on the extent to which NCMS covers inpatient cost.

Since take-up of the NCMS is voluntary, not every household participates. In 2006, among the four counties that offered the NCMS, $80 \%$ of the households had at least one person enrolled in the program. Although the NCMS in principle does not allow partial participation, we observe that $13 \%$ of the households had partial participation because some household members migrated out of the area for work and therefore were unlikely to enjoy the benefits of NCMS, or some members had a non-rural or non-local residential permit (hukou), hence were likely to have insurance coverage somewhere else.

The NCMS was offered to the whole area in 2007, with an average take-up rate of $86.74 \%$ in $2007,92.64 \%$ in 2008 and $93.37 \%$ in 2009 . In $2007,39.59 \%$ of the participating individuals received 
NCMS reimbursement. ${ }^{11}$ Conditional on receiving reimbursement, the average reimbursement was $76 \mathrm{RMB}$ per person, and over $250(0.013 \%)$ individuals received more than 10,000 RMB from the NCMS. With more government subsidies in 2009, 66.56\% of participating individuals received some form of NCMS reimbursement from January to November 2009, with an average reimbursement of 100.65 RMB per person, and over 700 (0.019\%) individuals received more than 10,000 RMB.

Given the fact that the 2005 per-capita income in the studied area was between 1500 and $2000 \mathrm{RMB}$, these numbers suggest that the NCMS is unlikely to offer much financial help for a healthy enrollee who only needs outpatient care for minor diseases. However, the NCMS could be a significant help if the enrollee needed hospitalization (e.g. for birth delivery), had a severe chronic disease (e.g. dialysis due to kidney failure) or had encountered a major acute health problem during the year. The $35-70 \%$ reimbursement rate and the restriction to designated providers and designated procedures imply that individual households still need to pay a large proportion of health care costs if they have severe diseases, and the out-of-pocket health care expenditure could be even higher if the NCMS motivates the insured to seek more treatment.

Due to the low probability of severe health events, we need a large sample to capture the events and their potential impact on a household's health- and non-health outcomes. In addition to the large sample size, our sample area is much poorer than the average in rural China, where the cost of health care is not proportional to household income. If the NCMS has any effects on health- and non-health outcomes, they should be likely to show up in our sample. These reasons lead us to believe that our data could provide better insights into the effects of the NCMS as compared to much

11 Reimbursement data are only available in county aggregate (from the local government reports). This is why we cannot examine whether NCMS has increased health care utilization at the household or individual level. 
smaller and probably more national representative samples used in Yi et al. (2009), Lei and Lin (2009) and Wagstaff et al. (2009).

The main part of the data was collected at the household level. ${ }^{12}$ By this design, we observe detailed household information including how many individuals reside in the household, their relationship to the household head, their age and gender composition, the amount of contract land, the amount of land in use, ownership of housing, the self-estimated value of house(s), ownership of durable goods, the availability of electricity, water and other amenities, whether the household has enrolled in the NCMS (for counties A to D), the number of household members that receive government subsidies, and the household engagement in various agricultural activities. The CAC does not collect data on household or personal income.

Individual-level data are limited to age, sex, education, employment, occupation, and the number of months away from home for out-of-township employment in 2006. Since a child in the studied area may get married as early as 17 and daughters often leave their own home after marriage, we restrict our definition of children to age $0-16$.

School age children are defined as anyone between 6 and 16 inclusive. According to the Law of Compulsory Education of China, the parent or legal guardian of a six-year-old (by September 1) is mandated to enroll the child in school; for the areas short of educational resources (like our study area), the compulsory education age may be delayed until seven. In other words, a seven year old in our sample area is required to enroll in school but the enrollment of a six year old can be voluntary.

\footnotetext{
12 The household head was asked to enter information for every family member. If a resident was away from home at the time of the interview, his/her information was still collected from the household. If the whole household had a registered residence in the studied area but was away from home at the time of interview, the village head would fill in the form for the household. Please see a more detailed description of this data set in Chen, Jin and Yue (2010).
} 
Given the lack of day care services in rural China, a six year old is most likely to stay at home if he or she is not enrolled in school. Compulsory education is free of tuition but parents need to pay fees for books and in-school activities, which in total might exceed 200 RMB per child per year. Children from far away families also need to pay for in-school boarding and meals, which could bring the total cost of schooling to as high as 500 RMB per year. Many children from extremely poor families cannot afford boarding and have to walk hours a day to school carrying lunch prepared from home. If the NCMS eases the financial burden on a household, it could make more resources available to support child schooling. It could also allow poor children to access health care services when they are sick and reduce the potential interruption of schooling due to illness. Note that the question that the CAC asked on school enrollment refers to whether a child is currently enrolled in primary or secondary school, not whether a child has attended school on a particular day. Because of this, we can capture lack of school enrollment due to major health problems but not school absence due to minor diseases.

Supplemental data were collected at the village level, including the size of the village in both arable land and registered population, whether the village is a place for minority gathering, the number of health care providers serving within the village, the distance to the nearest bus station ${ }^{13}$, elementary school, secondary school, and hospital, access to water, electricity and other amenities, whether the village has a national poverty status (as designated by the Central government), and how many young children (age 0-5) and pregnant women died during $2006 .{ }^{14}$ The data also include

\footnotetext{
13 The exact question is to the nearest bus/rail/dock station, but there is no railway station or major river in the studied area.

14 Due to potential measurement errors in the registered population, we calculate the number of adults per village from our study sample and use it to proxy for village population.
} 
several township level variables, namely the number and nature of township-village-enterprises, the distance between the township and county center, whether there is a highway exit within the boundary of the township, and the registered population of the township.

3. Data summary and simple analysis

Throughout the sample, $48.64 \%$ of the 5.9 million population was offered the NCMS in 2006 . Conditional on the four counties that offered the NCMS, $80 \%$ of households had at least one member enrolled in the NCMS. Breaking down this number by county, the household take-up rate was $75.7 \%$ for county A, $83.7 \%$ for county B, $78 \%$ for county C and $83.9 \%$ for county D. Figure 1 plots the histogram of household NCMS take-up rate at the village level, which ranges between 0 and 1 but is mostly concentrated between 0.7 and 1 .

Table 1 summarizes the village-level mortality of young children and pregnant women in NCMS and non-NCMS counties. As shown in the first two columns, NCMS counties have lower mortality than non-NCMS counties for both young children and pregnant women. Within the four NCMS counties, the median NCMS take-up rate at the village level is $84.1 \%$. And villages with an above-median NCMS take-up rate tend to have slightly lower mortality in both absolute count and mortality rate. ${ }^{15}$ These comparisons could reflect the beneficial effects of the NCMS or a selection bias if richer and healthier counties are more likely to adopt the NCMS early or if richer and healthier households are more likely to take-up the NCMS. We will address the selection issue in the

15 Child mortality rate is computed as the total number of 0-5 year old deaths divided by the sum of the death count and the total number of living 0-5 year olds in our sample. Maternal mortality rate is computed as the total number of pregnancy deaths divided by the sum of the death count and the total number of living 18-30 year old women in our sample. 
next Section.

Table 2 summarizes the enrollment rate of school-age children by NCMS status. The enrollment rate is almost 4 percentage points higher in NCMS counties than in non-NCMS counties ( $88.09 \%$ vs. $84.13 \%)$. Within the four NCMS counties, households enrolled in the NCMS are 2.3 percentage points more likely to have their children enrolled in school (88.55\% vs. $86.27 \%)$. Again, these raw differences could be driven by the NCMS or by selection. If we compare school enrollment rates by age the same pattern holds for every age level, but the differences are most obvious for ages 6, 7 and 16. One possible explanation is that financially constrained households are more likely to delay the start of child schooling or to stop child schooling immediately after the 9years of compulsory education. To the extent that the NCMS improves health and relieves a household's financial burden, it could increase child schooling, especially at the two ends of the school age range.

For a closer look at county-level selection, Table 3 lists the relevant fiscal condition, percapita income, demographics, percentage of migrating households, house value, and contract land for the eight counties in our sample. Fiscal condition and per-capita income are derived from the area's statistical year book and the rest come directly from the CAC data. On average, NCMS counties have relatively higher per-capita income and higher local fiscal income per capita. County D is the richest of the eight, while County A is almost the poorest of the four NCMS counties although it adopted the NCMS first (in 2004). Note that this comparison is relative within the study area. Overall, the study area is quite poor, with $50 \%$ of the population living in villages with national poverty status and with 
a percentage of school enrollment much lower than the national average (>95\%). ${ }^{16}$

Table 4 compares the average household and village characteristics of (1) households participating in the NCMS, (2) households not participating in the NCMS but living in NCMS counties, and (3) households living in non-NCMS counties. Overall the three groups are similar, but households in NCMS counties are slightly more educated, have a slightly smaller household size, have slightly higher house value, and are slightly less likely to live in villages with national poverty status. Similar differences exist between NCMS participating and non-participating households within NCMS counties.

Our first attempt to address the selection bias is controlling for observables. Denoting cty for county, $v$ for village, $h$ for household, and $i$ for individual, we regress the three main outcomes - village-level young child mortality (ChildMortality $v$ ), village-level pregnant women mortality (PregnancyMortality $)$, and individual-level schooling $\left(\operatorname{InSchool}_{i}\right)-$ on whether the residing county offered the NCMS in 2006 (NCMSoffered $_{c t y}$ ) and the extent to which the residents take up the NCMS (village take-up rate NCMStakeup $_{v}$ ) or an individual take-up dummy (NCMStakeup $i$ ), controlling for a number of village, household and individual attributes. In particular,

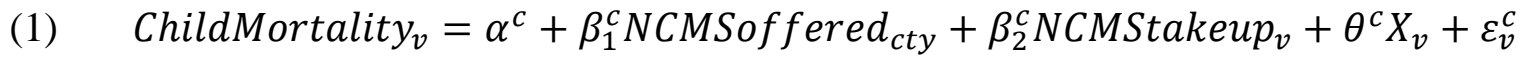

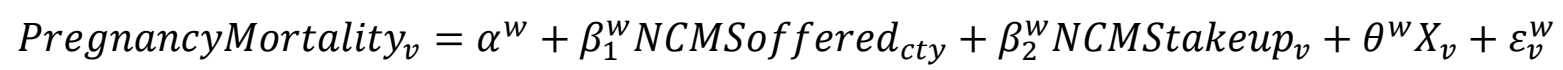

${ }^{16}$ In a news conference held by the Ministry of Education on February 28, 2006, Minister ZHOU Ji reported that the nationwide average enrollment rate for 9-year compulsory education is over $95 \%$. In particular, the nationwide enrollment rate is $99.15 \%$ for elementary school (grade 1-6) and 95\% for middle school (grade 7-9). Source: Ministry of Education ( http://www.moe.gov.cn/edoas/website18/11/info18511.htm), accessed at June 5, 2010. 
As shown in Table 1, the distribution of village-level mortality is concentrated at zero or one death. So we define ChildMortality $_{v}$ as a dummy of having any young child mortality in village $v$, and PregnancyMortality $v_{v}$ as a dummy of having any maternal mortality in village $v$. In an unreported table, we use the mortality rate instead and the results are similar.

The village attributes $\left(X_{v}\right)$ include village population, distance to the nearest bus station, distance to the nearest elementary school, distance to the nearest secondary school, distance to the nearest hospital as well as the village's poverty status and minority gathering status. The household attributes $\left(X_{h}\right)$ include house value (self-reported), contract land, whether any household member has migrated for a job out of the study area, number of 0-5 year olds, number of 6-16 year olds, number of 17-23 year olds, number of 24-44 year olds, number 45-59 year olds, number of 60+ year olds, and an indicator of the main source of income. The individual attributes $\left(X_{i}\right)$ include child age, gender, and birth order. If the NCMS is effective in improving health and reducing the financial burden of health care, we expect $\left\{\beta_{1}^{c}, \beta_{2}^{c}, \beta_{1}^{w}, \beta_{w}^{w}\right\}$ to be negative and $\left\{\gamma_{1}, \gamma_{2}\right\}$ to be positive, although all of them can be overestimated due to selection bias.

Table 5 reports the linear-probability OLS results for the two village-level dummies of whether there is any mortality in 0-5 year old children and pregnant women. Table 6 reports the linear-probability OLS results for the individual dummy of school enrollment. ${ }^{17}$ In both tables, we report one version without county dummies and one version with county dummies. The version without county dummies identifies the coefficient of NCMSoffered $d_{c t y}$. The other version

\footnotetext{
${ }^{17}$ We have tried negative binomial for the death count and probit for in school enrollment. Results are similar.
} 
absorbs NCMSoffered $_{c t y}$ in the county dummies and controls for the endogeneity of NCMS introduction. For school enrollment, we also report results for the full sample of 6-16 year olds and the sub-sample of 7-15 year olds separately.

Both tables confirm the impression from the raw data: NCMS counties have lower mortality and higher school enrollment, though the difference on the village-level mortality is not statistically significant. Conditional on residing in NCMS counties, households enrolled in the NCMS are 1.3-1.7 percentage points more likely to send their children to school compared with those not enrolled, but villages with higher NCMS take-up rates do not show significantly lower mortality.

To estimate the effect of the NCMS on school enrollment rate, a typical way to address the endogenous take-up of the NCMS is to find an instrumental variable that is correlated with an individual household's take-up decision but uncorrelated with the household's decision for children's school enrollment. Since the household is likely the unit of decision for both, such an instrument is difficult to find. One candidate we have considered is the percentage of elderly (age 60+) in other households of the same village. Age is likely to affect a household's take-up decision because the elderly are vulnerable to health risks and the existing claims and reimbursements are supposedly posted in the village. This positive correlation is confirmed in the data (with a first-stage t-statistics on the instrument equal to 2.35). When we use it as an instrument in equation (3), the coefficient of NCMStakeup $i$ is positive and insignificant with a magnitude roughly 30 times higher than the OLS coefficient. ${ }^{18}$ This leads us to conclude that the IV approach is not useful, either because the instrument is weak or is invalid.

${ }^{18}$ The 2SLS coefficient of NCMS take-up is 0.593 for 6-16 year olds and 0.346 for 7-15 year olds, using a sample of only NCMS counties. 
Another method to deal with the selection bias of NCMS take-up is propensity score matching. Conditional on the four NCMS counties, the classical propensity score matching will match one NCMS participating household with one non-participating household based on the predicted propensity of take-up and then compare the school enrollment outcome of the two households. Similar matching can be applied to village-level mortality, while the dependent variable of the propensity score prediction is the village-level NCMS take-up rate, not the individual decision of whether or not to enroll in the NCMS.

Table 7 shows the results of the classical cross-sectional propensity score matching, using a sample of the four NCMS counties only. In particular, we first use data from the NCMS counties to estimate the propensity of a household having at least one member participating in the NCMS. This prediction is not by individual because the CAC reports how many household members enroll in the NCMS but not who has enrolled. Among the $80 \%$ of households that participate in the NCMS, $13 \%$ participate partially because some household members have non-rural and non-local hukou or have migrated out of the area for work. These factors are controlled for in the propensity score prediction in addition to household size, number of children, number of the elderly, contract land, house value and village-level variables such as national poverty status, minority gathering status, whether the village is the center of a town, and the village's nearest distance to elementary school, secondary school and hospital. ${ }^{19}$ Many of these explanatory variables have statistically significant coefficients $(\mathrm{p}<0.01)$ in the probit estimation of the propensity score, but the overall pseudo R-square is not high (0.016 at the household level and 0.168 at the village level). The low household-level R-square is

\footnotetext{
${ }^{19}$ We have also tried to include household head education in the propensity score regression, but it is never statistically significant.
} 
comparable to what is reported in Wagstaff et al. (2009) Table 5 (0.010-0.044) and does not have a natural interpretation econometrically (Greene 2008). Even if the low pseudo R-square indicates an imperfect fit of the model, it highlights the presence of unobservables and therefore the importance of relaxing assumptions behind the classical cross-sectional propensity score matching estimators.

Once we identify the propensity score function, every participating household is matched with one non-participating household within the four NCMS counties, by both nearest neighbor matching and stratification matching. Since the two matching methods yield similar results, we report the result from nearest neighbor matching. The average treatment effect of NCMS take-up on school enrollment is presented in Panel A of Table 7. The result (0.016) is close to that of Table 5 (0.017), suggesting that either there is little selection bias in the OLS results or the classical propensity score matching does not address the selection bias either.

Panel B of Table 7 extends the propensity score prediction to the full sample, and allows an NCMS participating household to be matched with a similar household in a non-NCMS county. As shown in Figure 2, the propensity score distribution is similar across the two types of counties, except that the propensity score of non-NCMS counties has more density in the first (lower) mode and less density in the second (higher) mode. This is consistent with the poorer status of non-NCMS counties as shown in Table 3. Compared to the within-NCMS county matching, the propensity score matching across the two types of counties finds a larger effect of NCMS take-up on school enrollment (0.026 versus 0.016$)$, partly because the across-county comparison includes the fundamental difference between NCMS and non-NCMS counties.

We also use the NCMS counties to predict the average take-up rate per village as a function 
of village attributes and extend the prediction to the villages in non-NCMS counties. Since almost all the villages have a positive NCMS take-up rate, it is impossible to conduct village-level propensity score matching within the NCMS counties. Panel C of Table 7 presents the propensity score matching results when we match each village in the four NCMS counties with a village in a nonNCMS county. We find a negative effect of NCMS take-up rate on both types of mortality. Compared to OLS results, the effect on whether there is any 0-5 year old deaths is marginally significant.

Overall, raw data comparison across NCMS and non-NCMS counties, as well as OLS and propensity matching results suggest that the NCMS may have a significant effect on school enrollment. The effect of the NCMS on village-level mortality is negative as we expect, but statistically significant in raw data comparison, marginally significant in propensity score matching, and not significant in OLS.

4. Our methodology: DID in propensity score matching

In this section, we propose a new propensity score matching methodology to better utilize variations in our data. We observe outcomes for three sets of households: participants in the NCMS $\left(Y^{P}\right)$, non-participants in the NCMS $\left(Y^{N P}\right)$, and people not exposed to the NCMS $\left(Y^{N E}\right)$. The outcome of an NCMS-participating household $i_{P}$ depends on the household's observable attributes $\left(X_{i_{P}}\right)$, unobservables that are specific to NCMS-exposed counties, such as county investment in health care and education infrastructure $\left(W_{E}\right)$ and individual-specific unobservable attributes $\left(Z_{i_{P}}\right)$. Ideally, the average treatment effect (ATE) of enrolling in NCMS would be estimated as: 


$$
A T E=E\left[Y^{P}\left(X_{i_{P}}, W_{E}, Z_{i_{P}}\right)\right]-E\left[Y^{N P}\left(X_{i_{P}}, W_{E}, Z_{i_{P}}\right)\right] .
$$

However, the non-treatment outcome of the treated $Y^{N P}\left(X_{i_{P}}, W_{E}, Z_{i_{P}}\right)$ is not observed. Classical propensity score matching finds a non-participating household $i_{N P}$ in the same county that has the same observable attributes $\left(X_{i_{P}}=X_{i_{N P}}=X\right)$ and rewrites the average treatment effect estimator as:

$$
A T E_{P-N P}=E\left[Y^{P}\left(X, W_{E}, Z_{i_{P}}\right)\right]-E\left[Y^{N P}\left(X, W_{E}, Z_{i_{N P}}\right)\right] .
$$

If the two households differ in $Z$ (i.e. $Z_{i_{P}} \neq Z_{i_{N P}}$ ) and $Z$ affects the NCMS take-up decision, $A T E_{P-N P}$ is a biased estimator of $A T E$.

Another option is comparing household $i_{P}$ with a matched household $i_{N E}$ in the non-NCMS counties so that $X_{i_{P}}=X_{i_{N E}}=X$, which leads the average treatment effect to be estimated as:

$$
A T E_{P-N E}=E\left[Y^{P}\left(X, W_{E}, Z_{i_{P}}\right)\right]-E\left[Y^{N E}\left(X, W_{N E}, Z_{i_{N E}}\right)\right] .
$$

However, since we do not observe whether $i_{N E}$ would actually take up the NCMS should the NCMS be offered, it is likely that $Z_{i_{P}} \neq Z_{i_{N E}}$ due to the endogenous take-up of the NCMS in NCMS counties. County specific unobservables may differ as well due to the endogenous offer of $\operatorname{NCMS}\left(W_{E} \neq W_{N E}\right)$. Both suggest $A T E_{P-N E}$ is a biased estimator of $A T E$.

To alleviate the selection bias, consider two groups of households in all counties: the first group has high take-up propensity based on their observable attributes $\left(X^{h}\right)$ and the second group has low take-up propensity because of their different observables $\left(X^{l}\right)$. Because $X^{h} \neq X^{l}$, the two groups are likely to differ in unobservables as well $\left(Z^{h} \neq Z^{l}\right)$. Each group may contain NCMSparticipating, NCMS-non-participating, and NCMS-non-exposed households. If we compare highpropensity households between NCMS-exposed $(E)$ and non-NCMS-exposed $(N E)$ counties and assume the probability of taking up NCMS condition on $X^{h}$ is $P R^{h}$, we get: 


$$
\begin{aligned}
& A T E_{E-N E}^{h}=E\left[Y^{E}\left(X^{h}, W_{E}, Z_{i_{E}}^{h}\right)\right]-E\left[Y^{N E}\left(X^{h}, W_{N E}, Z_{i_{N E}}^{h}\right)\right] \\
= & P R^{h} E\left[Y^{P}\left(X^{h}, W_{E}, Z_{i_{E}}^{h}\right)\right]+\left(1-P R^{h}\right) E\left[Y^{N P}\left(X^{h}, W_{E}, Z_{i_{E}}^{h}\right)\right]-E\left[Y^{N E}\left(X^{h}, W_{N E}, Z_{i_{N E}}^{h}\right)\right]
\end{aligned}
$$$$
=P R^{h}\left\{E\left[Y^{P}\left(X^{h}, W_{E}\right)\right]-E\left[Y^{N E}\left(X^{h}, W_{N E}\right)\right]\right\}+\left(1-P R^{h}\right)\left\{E\left[Y^{N P}\left(X^{h}, W_{E}\right)\right]-E\left[Y^{N E}\left(X^{h}, W_{N E}\right)\right]\right\}
$$

under the assumption that household-specific unobservables follow the same statistical distribution conditional on $X^{h}$ in NCMS and non-NCMS counties $\left(f\left(Z_{i_{E}}^{h} \mid X^{h}\right)=f\left(Z_{i_{N E}}^{h} \mid X^{h}\right)\right)$. Note that this assumption is weaker than what is assumed in classical propensity matching $\left(f\left(Z_{i_{P}}^{h} \mid X^{h}\right)=\right.$ $f\left(Z_{i_{N P}}^{h} \mid X^{h}\right)$ or $\left.f\left(Z_{i_{P}}^{h} \mid X^{h}\right)=f\left(Z_{i_{N E}}^{h} \mid X^{h}\right)\right)$ because $Z_{i_{E}}^{h}$ is for any high propensity household $i$ in NCMS exposed counties that does not depend on the NCMS actual take-up status but $Z_{i_{P}}^{h}$ and $Z_{i_{N P}}^{h}$ do. The assumption of $f\left(Z_{i_{E}}^{h} \mid X^{h}\right)=f\left(Z_{i_{N E}}^{h} \mid X^{h}\right)$ is more likely to be satisfied in our data because the two types of counties are similar in the distribution of population, although their county specific unobservables can differ $\left(W_{E} \neq W_{N E}\right)$. Similarly, under the assumption of $f\left(Z_{i_{E}}^{l} \mid X^{l}\right)=f\left(Z_{i_{N E}}^{l} \mid X^{l}\right)$, we have for the low propensity group:

$$
\begin{gathered}
=P R^{l} E\left[Y^{P}\left(X^{l}, W_{E}, Z_{i_{E}}^{l}\right)\right]+\left(1-P R^{l}\right) E\left[Y^{N P}\left(X^{l}, W_{E}, Z_{i_{E}}^{l}\right)\right]-E\left[Y^{N E}\left(X^{l}, W_{N E}, Z_{i_{N E}}^{l}\right)\right] \\
=P R^{l}\left\{E\left[Y^{P}\left(X^{l}, W_{E}\right)\right]-E\left[Y^{N E}\left(X^{l}, W_{N E}\right)\right]\right\}+\left(1-P R^{l}\right)\left\{E\left[Y^{N P}\left(X^{l}, W_{E}\right)\right]-E\left[Y^{N E}\left(X^{l}, W_{N E}\right)\right]\right\} .
\end{gathered}
$$

If we further assume that the influence of $\mathrm{X}$ and $\mathrm{W}$ on $\mathrm{Y}$ is separable (i.e. $E[Y(X, W)]=$ $g_{x}(X)+g_{w}(W)$ ), the average treatment effect (ATE) of the NCMS is the same for high and low propensity groups, and the treatment effect does not arise until the NCMS is in effect, we can write the difference between (7) and (8) as a DID propensity score estimator:

$$
A T E_{D I D}=A T E_{E-N E}^{h}-A T E_{E-N E}^{l}
$$

$$
=P R^{h}\left\{E\left[Y^{P}\left(X^{h}, W_{E}\right)\right]-E\left[Y^{N E}\left(X^{h}, W_{N E}\right)\right]\right\}+\left(1-P R^{h}\right)\left\{E\left[Y^{N P}\left(X^{h}, W_{E}\right)\right]-E\left[Y^{N E}\left(X^{h}, W_{N E}\right)\right]\right\}
$$




$$
\begin{aligned}
& -P R^{l}\left\{E\left[Y^{P}\left(X^{l}, W_{E}\right)\right]-E\left[Y^{N E}\left(X^{l}, W_{N E}\right)\right]\right\}-\left(1-P R^{l}\right)\left\{E\left[Y^{N P}\left(X^{l}, W_{E}\right)\right]-E\left[Y^{N E}\left(X^{l}, W_{N E}\right)\right]\right\} \\
= & P R^{h}\left\{A T E^{h}+g_{w}\left(W_{E}\right)-g_{w}\left(W_{N E}\right)\right\}+\left(1-P R^{h}\right)\left\{g_{w}\left(W_{E}\right)-g_{w}\left(W_{N E}\right)\right\} \\
& -P R^{l}\left\{A T E^{l}+g_{w}\left(W_{E}\right)-g_{w}\left(W_{N E}\right)\right\}-\left(1-P R^{l}\right)\left\{g_{w}\left(W_{E}\right)-g_{w}\left(W_{N E}\right)\right\} \\
= & P R^{h}\left\{A T E^{h}\right\}-P R^{l}\left\{A T E^{l}\right\}=\left(P R^{h}-P R^{l}\right) \cdot A T E .
\end{aligned}
$$

In other words, we can difference out the county specific unobservables between NCMS and nonNCMS counties, hence circumventing the endogenous offering of NCMS by county. This way we identify the true $A T E$ as a proportion of $A T E_{D I D}$. Alternatively, $A T E_{D I D}$ can be interpreted as the average treatment effect of randomly increasing NCMS enrollment from $P R^{l}$ to $P R^{h}$.

Note that our DID estimator utilizes three groups: (1) those who take up NCMS in the NCMS counties, (2) those who do not take up NCMS in the NCMS counties, and (3) those living in the nonNCMS counties. The endogenous individual take-up is controlled for by comparing observationally similar households between NCMS and non-NCMS counties, while the endogenous introduction of NCMS at the county level is controlled for by comparing high propensity households and low propensity households within the same type of county.

The effectiveness of $A T E_{D I D}$ hinges on three assumptions: first, county-specific unobservables $(W)$ apply to everyone in the same county so that $W$ can be differenced out. Second, conditional on $X$, the unobservable individual attributes $(Z)$ follow the same distribution between NCMS and non-NCMS counties. Note that this does not require $Z$ to be distributed the same for all values of $X$. For example, if $\mathrm{Z}$ represents the attitude for child schooling and $\mathrm{X}$ represents education level of the household head, we assume that households with the same household head education have the same distribution of schooling attitude in NCMS and non-NCMS counties, but high- and 
low-education households could have different schooling attitudes. The third assumption is that the average treatment effect (which by definition does not occur until the household is enrolled in the NCMS) is the same for all NCMS-participating households.

We argue that $A T E_{D I D}$ is better than classical propensity score matching estimates $\left(A T E_{P-N P}\right.$ or $\left.A T E_{P-N E}\right)$, because we do not directly compare NCMS participants versus those that do not participate or are not exposed to NCMS. More specifically, Wang et al. (2009) and Wagstaff et al. (2009) propose estimators similar to $A T E_{P-N E} \cdot{ }^{20}$ This is still biased because insurance participants are a selected group and the distribution of $Z_{i_{P}}$ could be systematically different from $Z_{i_{N E}}$ even if the two sets of counties are overall comparable. In contrast, we compare the population of NCMS and non-NCMS counties regardless of the household's actual NCMS take-up decision. Therefore, we get around the unobserved selection of NCMS take-up and weaken the assumption from similarity between $Z_{i_{P}}$ and $Z_{i_{N E}}$ to similarity between $Z_{i_{E}}$ and $Z_{i_{N E}}$ (conditional on $\mathrm{X}$ ). Moreover, our DID design differences out county-specific unobservables, which enables comparison between NCMS and non-NCMS counties even if the offering of NCMS is endogenous.

\section{Results}

To calculate our DID estimator, we pool the eight counties and divide the overall householdlevel propensity score distribution equally into 10 bins by the percentile of the distribution. ${ }^{21}$ For example, bin 1 refers to the lowest 10 percent of the propensity score distribution, bin 2 refers to the

\footnotetext{
20 Both Wang et al. (2009) and Wagstaff et al. (2009) have data before and after the insurance offer, so their estimate, if translated in our framework, is equivalent to $A T T_{P-N E}$ for $\mathrm{Y}$ that represents the before-after change of outcomes within a household.

${ }^{21}$ We have tried 20 bins with $5 \%$ of data in each bin. Results are very similar.
} 
lowest $10-20 \%$, and bin 10 refers to the highest $10 \%$. Using $k$ as the index of bin, we estimate:

$$
\text { InSchool }_{i}=\sum_{k=1}^{10} \alpha_{k}+\beta \cdot X_{i}+\sum_{c t y=1}^{8} \delta_{c t y}+\sum_{k=2}^{10} \phi_{k} \cdot \text { NCMSoffered }_{c t y}+\varepsilon_{i}
$$

where $\left\{\delta_{c t y}\right\}$ are the eight county dummies, in an attempt to capture county-by-county difference in school enrollment, and $\left\{\phi_{k}\right\}$ is the DID estimator for bin $k$ as compared to bin 1 . Since bin 1 has the lowest propensity score, a positive effect of the NCMS would be reflected as $\phi_{k}>0$ for all $k=2,3, \ldots 10$. and the magnitude of $\phi_{k}$ would increase with $k$.

Following the same logic, we can conduct the DID estimator at the village level for both types of mortality. Since we have significantly fewer counts of villages (3977) than individuals (1.4 million), we use 5 instead of 10 bins for the village-level estimation:

$$
\begin{aligned}
& \text { ChildMortality }_{v}=\sum_{k=1}^{5} \alpha_{1 k}+\beta_{1} X_{v}+\sum_{c t y=1}^{8} \delta_{1 c t y}+\sum_{k=2}^{5} \phi_{1 k} \cdot \text { NCMSoffered }_{c t y}+\varepsilon_{1 v} \\
& \text { PregMortality }_{v}=\sum_{k=1}^{5} \alpha_{2 k}+\beta_{2} X_{v}+\sum_{c t y=1}^{8} \delta_{2 c t y}+\sum_{k=2}^{5} \phi_{2 k} \cdot \text { NCMSoffered }_{c t y}+\varepsilon_{2 v} .
\end{aligned}
$$

In Table 8 we first summarize the distribution of the predicted village-level NCMS take-up rate in the two types of counties. The two distributions are similar in mean, standard deviation, minimum and maximum. Panel B of Table 8 reports the DID estimators for village-level mortality. Using the lowest $20 \%$ of villages (in terms of predicted take-up rate) as the benchmark, we find that all of the interactions between the bin dummies and NCMSoffered are negative but statistically insignificant. These estimates suggest that the NCMS has no obvious effect in reducing the incidence of child or maternal mortality at the village level, a result consistent with the OLS regression reported in Table 3.

Before we present the DID estimators on individual-level school enrollment, Figure 3 plots the average of InSchool $_{i}$ for bins 1-10 in NCMS and non-NCMS counties separately. Within the 
non-NCMS counties, the average of InSchool $_{i}$ is $85.6 \%$ for the $9^{\text {th }}$ bin (top 10-20\% of the propensity score) and $83.7 \%$ for the $1^{\text {st }}$ bin (lowest $0-10 \%$ of the propensity score). The $1.9 \%$ difference filters out the county-level unobservables $(W)$ and therefore reflects the fundamental difference between the two bins when there is no NCMS. Similarly, the difference between the $1^{\text {st }}$ and $9^{\text {th }}$ bins is $89.4 \%-87 \%=2.4 \%$ in NCMS counties. According to Section 4 , the DID estimator can be computed by $2.4 \%-1.9 \%=0.5 \%$, which we interpret as the average treatment effect of an increasing NCMS take-up rate from the propensity of the $1^{\text {st }}$ bin $(0.71)$ to the propensity of the $9^{\text {th }}$ bin $(0.872) .^{22}$

Following this logic, equation (10) identifies the DID estimator $\left(\phi_{k}\right)$ for every bin $k=2,3, \ldots 10$. Compared to Figure 3 , equation (10) allows unobservable county attributes to differ among each county and lets InSchool $_{i}$ vary by individual attributes such as age, gender, and birth order. These individual attributes do not enter into the propensity score prediction because the prediction is done at the household level.

Table 9 reports the DID estimators for bins $k=2,3, \ldots 10$. Unlike the OLS and classical propensity score matching results, these DID estimators are all statistically zero, suggesting that the NCMS has no significant effect on school enrollment once we control for the endogeneous introduction and take-up of the NCMS.

To make a more straightforward comparison between our DID estimate and the classical

22 Similar comparison can be conducted between bin 1 and bin 10 . We do not have a compelling explanation as to why the average school enrollment of bin 10 is lower than that of bin 9 . One possibility is that families of bin 10 are more likely to have a family member that migrates or holds a non-rural hukou out of the study area, both of which could lead to more measurement errors in school enrollment. In our DID estimate, we explicitly control for the systematic differences across bins. 
propensity score estimate, we add the dummy of NCMStakeup to equation (10):

$$
\begin{aligned}
\text { InSchool }_{i}= & \sum_{k=1}^{10} \alpha_{k}+\beta \cdot X_{i}+\sum_{c t y=1}^{8} \delta_{c t y} \\
& +\sum_{k=2}^{10} \rho_{k} \cdot \text { NCMSoffered }_{c t y}+\sum_{k=2}^{10} \mu_{k} \cdot \text { NCMStakeup }_{i}+\varepsilon_{i}
\end{aligned}
$$

To avoid confusion, we use a different Greek letter for the coefficient of NCMSoffered $\left(\rho_{k}\right)$ because the interpretation of this coefficient will be different from that of $\phi_{k}$. Following the notation of Section $4, \phi_{k}$ compares households exposed to the NCMS with households not exposed to the NCMS thus representing the average treatment effect of the NCMS (proportional to the propensity of enrolling in the NCMS relative to the lowest propensity group). In comparison, $\mu_{k}$ captures the difference between NCMS participants and non-participants (both exposed to NCMS), which corresponds to $A T E_{P-N P} ; \rho_{k}$ captures the difference between the non-exposed and the exposedbut-not-participating; and $\mu_{k}+\rho_{k}$ captures the difference between participants and the non-exposed $\left(A T E_{P-N E}\right)$. The DID estimator $\phi_{k}$ should be somewhere between $\rho_{k}$ and $\mu_{k}+\rho_{k}$.

Table 10 reports the estimates of $\rho_{k}$ and $\mu_{k}$ for $k=2,3, \ldots 10$. Consistent with the classical propensity score matching results (as reported in Table 7), we find 8 out of the $9 \mu_{k} \mathrm{~s}$ are statistically significant. Interestingly, none of the $\rho_{k}$ s are significant. Comparing Tables 9 and 10, we conclude that most of the observed school enrollment differences between NCMS participating and non-NCMS participating households are due to selection. In other words, the classical propensity score matching estimate (in Table 7) has failed to control the selection bias due to unobservable individual attributes. The propensity score matching between NCMS and non-NCMS counties $\left(A T E_{P-N E}\right)$ is even worse because it does not control for the across-county difference either.

Is it possible that the NCMS was introduced too soon to have any real effect on school 
enrollment by 2006 ? The second column of Table 9 compares county A (the one that introduced the NCMS in 2004) versus the other four non-NCMS counties. This column shows no positive effect of the NCMS either: two of the eight DID estimators are even negative, with $95 \%$ confidence.

So far, we conclude that the NCMS has no positive effect on mortality and school enrollment for the average population. One possible explanation for the zero average treatment effect is that the NCMS is only effective on a small fraction of the population that is most vulnerable to health risk (Levy and Meltzer 2008). To examine this explanation, we try to identify vulnerable populations in six ways: (1) age 6,7,8,9-14 and 15-16; (2) boys versus girls; (3) households with and without elderly; (4) households with a low and high house value; (5) households with a low and high percentage of household members being adult laborers; and (6) household heads with lower- or higher-than median education.

Arguably, younger age children are more vulnerable either because they are more likely to be sick or because the enforcement of compulsory schooling is weaker at a younger age (especially six years old, given the law's permission to delay the school start age until seven year old if the area is short of educational resources); girls are more vulnerable because households tend to give priority to boys' education; households with elderly are more subject to health risks of the elderly; and households with a lower house value and/or lower education of the household head are more vulnerable because they are likely to be poorer. These arguments predict that the NCMS may have more beneficial effects on six year olds, girls, households with elderly members, and households with a lower house value or lower education level for the household head. The difference between households with relatively more or less adult laborers is less clear: those with less adult laborers are 
more vulnerable to health risk, but those with more adult laborers could enjoy a greater gain of total labor productivity due to health improvements associated with more labor.

Table 11 reports the DID estimators for children aged 6, 7, 8, 9-14, and 15-16 separately. We examine the lower end of the age range in more detail because Table 2 shows that ages 6 and 7 have the lowest enrollment rates and the highest variation between NCMS and non-NCMS counties. This leads us to suspect that uninsured households may delay the school starting age of their children due to lack of financial resources for education, lack of access to health care, or both. As we expect, Table 11 shows that the NCMS only has significant effects on school enrollment at age 6, and close to zero effect on older children. Even for age 6, only 3 of the 9 interactions of the propensity score bin and NCMSoffered are statistically significant, suggesting that the effects of the NCMS on reducing the delay of elementary school enrollment are moderate and only present for the households with relatively high propensity scores. ${ }^{23}$

One may argue that parents want to delay child schooling not due to a lack of financial resources but out of concern that a child younger than the average in his/her class may not have good opportunities to develop leadership and other social skills. We have two reasons to argue against this interpretation. First, if the delay is due to the concern about social skills, the introduction and take-up of the NCMS does not affect this concern and therefore should not have any effect on school starting age. Second, Chinese families that have more financial resources tend to push for early enrollment instead of for delayed schooling. For example, in the China Health and Nutrition Survey (CHNS), a longitudinal sample of Chinese households in nine provinces, the six-year-old enrollment rate is

${ }^{23}$ In an unreported table, we repeat the exercise for 16-year-olds alone but do not find any significant effect of NCMS on school enrollment. 
significantly higher in urban households $(65.1 \%)$ than in rural households $(56.6 \%)$. The comparison is similar if we divide the CHNS sample by whether a household's per-capita income is above or below the sample median: the six-year-old enrollment rate is $63.37 \%$ in above-median households and $58.36 \%$ in below-median households.

In addition, Guo et al. (2007) show that urban China has an alarmingly high rate of caesarean section (c-section) deliveries in hospital-based births (between 26\% and 63\% during the late 1990s), as compared to the World Health Organization recommended level of 15\%. At least anecdotally, part of this is attributable to a rush of c-section deliveries in urban China towards the end of August because the requirement for compulsory school enrollment is being six years old by September $1 .^{24}$ To address the parental cry for early enrollment, the Ministry of Education is considering a proposal that allows five year olds to enroll in elementary school if the child has received kindergarten education and the local area has enough educational resources to admit them. ${ }^{25}$ Based on these facts and our DID estimates, it is plausible that the introduction of the NCMS has led to less delay of schooling, either because NCMS relieves the financial burden of health care or because better access to health care makes more six-year-olds healthy enough for school. Unfortunately, we do not have individual-level health utilization data to distinguish these two explanations.

Table 12 reports the DID estimators by the percentage of household members that are adult laborers (age 17-60). In particular, we divide the households into four quartiles and obtain a separate set of parameters for each quartile. The DID estimates are mostly insignificant, except for 4

\footnotetext{
${ }^{24}$ See http://dailynews.sina.com/bg/chn/chnnews/chinanews/su/20100914/04411830677.html, accessed on September $14,2010$.

25 See http://edu.ce.cn/young/campus/200912/07/t20091207_20566049.shtml, accessed on September 11, 2010.
} 
coefficients for households in the third quartile, 1 coefficient for the first quartile and 1 coefficient for the fourth quartile. This suggests that, even if the NCMS has improved the health of adult laborers, increased their labor income, and made more financial resources available for child schooling, the effect is sparse and non-linear.

For other sub-groups (not reported), we find no more than one statistically significant DID estimate by child gender, by whether a household has elderly members, by house value, and by household head education. These results, combined with the above results by child age and adult laborers, imply that the NCMS is not effective in improving school enrollment among the most vulnerable households, though there is some evidence that the NCMS has reduced the delay of elementary education for six-year-olds.

\section{Discussion and Conclusion}

Overall, the raw data of a large cross-section from the 2006 China Agricultural Census suggests that NCMS-insured households on average have better outcomes in child school enrollment, young child mortality, and maternal mortality than do non-insured households. However, most of these differences are driven by the endogenous introduction and take-up of the NCMS. Once we control for the selection bias using a difference-in-difference propensity score method, the NCMS has close to zero effect on the average population, although there is moderate evidence that it has reduced the delay of elementary education for some six-year-olds.

This finding of zero average treatment effect is consistent with the existing literature (Yi et al. 2009; Lei and Lin 2009), who attribute the lack of effect (on health care utilization and health 
improvement) to the low reimbursement rate and to selection. Wang et al. (2009) do find some positive effects of health insurance coverage on self-reported health status, but the insurance program they studied is different from the NCMS and arguably more comprehensive in outpatient care and could offer more help to deal with non-catastrophic health risk.

Since our studied area is much poorer than most areas of China, we suspect that the NCMS does not improve the three studied outcomes in other areas either. In addition to the low reimbursement rate, as noted above, the lack of average effect may be explained by the fact that mortality is an extreme event and the effect of the NCMS on school enrollment may take more than three years to show up in the data. Another possibility is that the NCMS may encourage more health care utilization but the ease of financial burden has not appeared yet, as households need to pay even more money out of pocket when they seek more treatment. Wagstaff et al. (2009) confirm this suspicion: they find that the NCMS is related to more health care utilization but that it does not decrease out-of-pocket spending on health care except for infant deliveries. Thanks to increased government subsidies in 2009 , the reimbursement rate has increased over time. Whether this improvement portends better health and educational outcomes is a topic worth studying in the future.

\section{References}

Chen, Shaohua and Martin Ravallion (2008) "The developing world is poorer than we thought, but no less successful in the fight against poverty," Policy Research Working Paper \#4703, World Bank.

Chen Y, Xu X, Wang R, Zhang H, Wu N, Wang L, Luo W, Wang Z. (2005) 'Evaluation of the effect of NCMS on poverty reduction due to illness." Chinese Health Economics 24(8): 26-28 (in Chinese)

Chen, Yuyu; Ginger Zhe Jin and Yang Yue (2010) "Peer Migration in China", NBER working paper \#15671. 
Cheng Bin; Wang Zaoli; and Yang Zhiyong (2008) "The Influence of the New-Type Rural Cooperative Medical System on Promoting Hospital Delivery of Pregnant Women in Rural Areas" Maternal and Child Health Care of China, 2008 23(10): 1323-1324 (in Chinese).

Chou, Win Lin and Zijun Wang (2009) "Regional Inequality in China's Health Care Expenditures" Health Economics 18: S137-S146.

Chou, Shin-Yi; Jin-Tan Liu and James K. Hammit (2006), "Households' Precautionary Behaviors The Effects of the Introduction of National Health Insurance in Taiwan," Review of Economics of the Household, 4(4), 395-421, 2006.

Chou, Shin-Yi; Michael Grossman and Jin-Tan Liu (2011) "The Impact of national Health Insurance on Birth Outcomes: A Natural Experiment in Taiwan” NBER working paper \#16811.

Currie, Janet and Jonathan Gruber (1996a) "Health Insurance Eligibility, Utilization of Medical Care, and Child Health." Quarterly Journal of Economics. 111: 431-66.

Currie, Janet and Jonathan Gruber (1996b) "Saving Babies: The Efficacy and Cost of Recent Expansions of Medicaid Eligibility for Pregnant Women.” Journal of Political Economy. 104:126396.

Currie, Janet (2009) "Healthy, Wealthy, and Wise: Socioeconomic Status, Poor Health in Childhood, and Human Capital Development” Journal of Economic Literature, 47(1): 87-122.

Dafny, Leemore and Jonathan Gruber. 2005. "Public Insurance and Child Hospitalizations: Access and Efficiency Effects," Journal of Public Economics 89(1): 109-129.

Dahl, Gordon and Lance Lochner (2005) "The Impact of Family Income on Child Achievement" NBER working paper \#11279.

Fang Lilin; Yuan Zhaokang; Xiao Yunchang; Hong Ying; Cheng Hongliang; and Wang Jinfu (2006) "A Comparative Analysis of the Equitability of Health Service before and after the Implementation of the New Rural Cooperative Medical System" Chinese Rural Health Service Administration, 2006 26(5): 6-8 (in Chinese).

Glewwe, Paul and Edward A. Miguel (2008) "The Impact of Child Health and Nutrition on Education in Less Developed Countries" Handbook of Development Economics, Volume 4, Chapter 56, Elsevier.

Greene, William H. (2008) Econometric Analysis, $6^{\text {th }}$ Edition, Prentice Hall.

Guo, Sufang; Sabu S. Padmadas; Zhao Fengmin; James J Brown; and R William Stones (2007) "Delivery settings and caesarean section rates in China" Bulletin of the World Health Organization 
85(10): October 2007, 733-820. Accessed at http://www.who.int/bulletin/volumes/85/10/06035808/en/index.html.

Heckman, James, Hidehiko Ichimura and Petra Todd (1997): "Matching As An Econometric Evaluation Estimator: Evidence from Evaluating a Job Training Program," Review of Economic Studies, 64(4), 605-654.

Heckman, James, Hidehiko Ichimura, Jeffrey Smith and Petra Todd (1998): "Characterizing Selection Bias Using Experimental Data," Econometrica , 66(5), 1017-1098.

Imbens Guido (2004) "Nonparametric estimation of average treatment effects under exogeneity: a review" The Review of Economics and Statistics 86(1): 4-29.

Joyce, Ted and Andrew Racine (2005) "Chip Shots: Association Between the State Children's Health Insurance Programs and Immunization Coverage and Delivery." Pediatrics 115(5): e526e534.

Lei, Xiaoyan and Wanchuan Lin (2009) "The New Cooperative Medical Scheme in Rural China: Does More Coverage Mean More Service and Better Health?" Health Economics 18(S2), 2009, S25-S46.

Levine, Phillip and Diane Whitmore Schanzenbach (2009) "The Impact of Children's Public Health Insurance Expansions on Educational Outcomes" Forum for Health Economics \& Policy, Berkeley Electronic Press 12(1).

Levy, Helen and David Meltzer. 2008. "The Impact of Health Insurance on Health" Annual Review of Public Health 29:399-409.

Liao Xiaoning (2009) "The Effects of Jiangxiao Project and the New Rural Cooperative Medical System on Improving Hospital Delivery Ratio of Pregnant Women in Poor Rural Areas" Chinese Primary Health Care, 2009 23(2):43 (in Chinese).

Liu Y, Hsiao WC, Eggleston K. 1999. Equity in health and health care: the Chinese experience. Social Science and Medicine 49: 1349-1356.

LoSasso, Anthony and Thomas Buchmueller. 2004. "The Effect of the State Children's Health Insurance Program on Health Insurance Coverage." Journal of Health Economics. 23:1059-82.

Lu Liping and Li Xueqing (2010) "The Effects of the New-Type Rural Cooperative Medical System on Reducing the Mortality of the Pregnant and Lying-in Women in China" Medical Information, 2010 5(10):2985-2986 (in Chinese). 
Miller, Grant; Diana M. Pinto and Marcos Vera-Hernández (2009): "High-Powered Incentives in Developing Country Health Insurance: Evidence from Colombia's Régimen Subsidiado" NBER working paper \#15456.

Ministry of Health PRC (1999) Research on National Health Services: An Analysis Report of the Second National Health Services Survey in 1998 (I), Beijing.

Ministry of Health, PRC (2005) Handbook of Statistics on New Cooperative Medical System 20032004. Department of Rural Health Management and Center for China Cooperative Medical Scheme of MOH: Beijing.

Ministry of Health, PRC (2007) Guideline on the Management of New Cooperative Medical System (2007 version). Department of Rural Health Management and Center for China Cooperative Medical Scheme of MOH: Beijing.

Morris, Pamela; Greg Duncan and Christopher Rodrigues (2004) "Does Money Really Matter? Estimating Impacts of Family Income on Children's Achievement with data from Random Assignment Experiments" Northwestern University working paper.

Nyman J and Barleen N. (2005) “The Effect of Supplemental Private Health Insurance on Health Care Purchases, Health, and Welfare in Brazil" University of Minnesota: Minneapolis, MN.

Rosenbaum, Paul and Donald Rubin (1983) "The Central Role of the Propensity Score in Observational Studies for Causal Effects," Biometrika, 70,41-55.

Russel M. (2005) “Applying DALY to assessing national health insurance performance: the relationship between the national health insurance expenditures and the burden of disease measures in Iran" International Journal of Health Planning \& Management 20(2): 89-98.

Shi Qingling (2008) "The Promoting Effects of New-Type Rural Cooperative Medical System on Hospital Delivery of Rural Areas Pregnant Women" Maternal and Child Health Care of China, 2008 (18):2492-2492 (in Chinese).

Smith, Jeffrey and Petra Todd (2005): "Does Matching Overcome Lalonde's Critique of Nonexperimental Estimators?" Journal of Econometrics, 125 (1-2), p. 305-353.

Trivedi, P. (2003) "Patterns of health care use in Vietnam: analysis of 1998 Vietnam Living Standards Survey data" in Glewee, P., Agrawal, N., and Dollar, D. edited Economic Growth, Poverty and Household Welfare: Policy Lessons from Vietnam. World Bank, Washington DC.

Wagstaff, A. and M. Pradhan (2005) "Health Insurance Impacts on Health and Nonmedical Consumption in a Developing Country" The World Bank: Washington, DC. 
Wagstaff, A and S. Yu (2007) "Do health sector reforms have their intended impacts? The World Bank's Health VIII project in Gansu province, China" Journal of Health Economics 26: 505-535.

Wagstaff, A. and M. Lindelow (2008) "Can insurance increase financial risk? The curious case of health insurance in China" Journal of Health Economics 27(4): 990-1005.

Wagstaff, A.; M. Lindelow; Gao Jun; Xu Ling; and Qian Juncheng (2009) "Extending health insurance to the rural population: An impact evaluation of China's new cooperative medical scheme" Journal of Health Economics 28: 1-19.

Wang, Hong; Winnie Yip; Licheng Zhang; and William C. Hsiao (2009) "The Impact of Rural Mutual Health Care on Health Status: Evaluation of a Social Experiment in Rural China" Health Economics 18: S65-S82 (2009).

Wang Weizhong (2007) "Analysis on the in-Patient Services Utilization Before and After Enforcing the New-Type Rural Cooperative Medical System in County-level City of Tong Xiang" Chinese Primary Health Care, 2007, 21(9):12-14 (in Chinese).

The World Health Report 2005, accessed at www.who.int/whr/2005/en/index.html on August 15, 2011.

Yuan Z; Fang L.; Zhou X.; Xian Y.; Hong Y.; Cheng H.; and Wang J. (2006) "Impact of NCMS on farmers' demand and utilization for medical care: a follow-up survey” Chinese Rural Health Service Administration 26(10): 14-17 (in Chinese).

Yi, Hongmei; Linxiu Zhang; Kim Singer; Scott Rozelle; and Scott Atlas (2009) "Health Insurance and Catestrophic Illness: a Report on the New Cooperative Medical System in Rural China" Health Economics 18: S119-S127 (2009).

Zhang L; Yan Y.; S. Rozelle; and Wang H. (2006) "An empirical analysis of China's New Collective Medical System: from a policy prospective.” Social Sciences in China XXVII(3): 107-116.

Zhang Tihua; Tian Qingfeng; and Shi Songhe (2007) "A Study of the New-Type Rural CMS Influence on Outpatient Service Utilization of Peasants" Chinese Journal of Misdiagnostics, 2007 7(28): 6951-6952 (in Chinese).

Zhu Dongmei; Jin Guoping; Wu Hui; Zhang Dongxia; and Tian Qingfeng (2007) "Study of Utilization of Hospital Health Service before and after the New Rural Cooperatives Medical Scheme" Henan Medical Research, 2007 16(3): 261-264 (in Chinese). 
Figure 1: Histogram of village-level take-up rate, conditional on NCMS counties

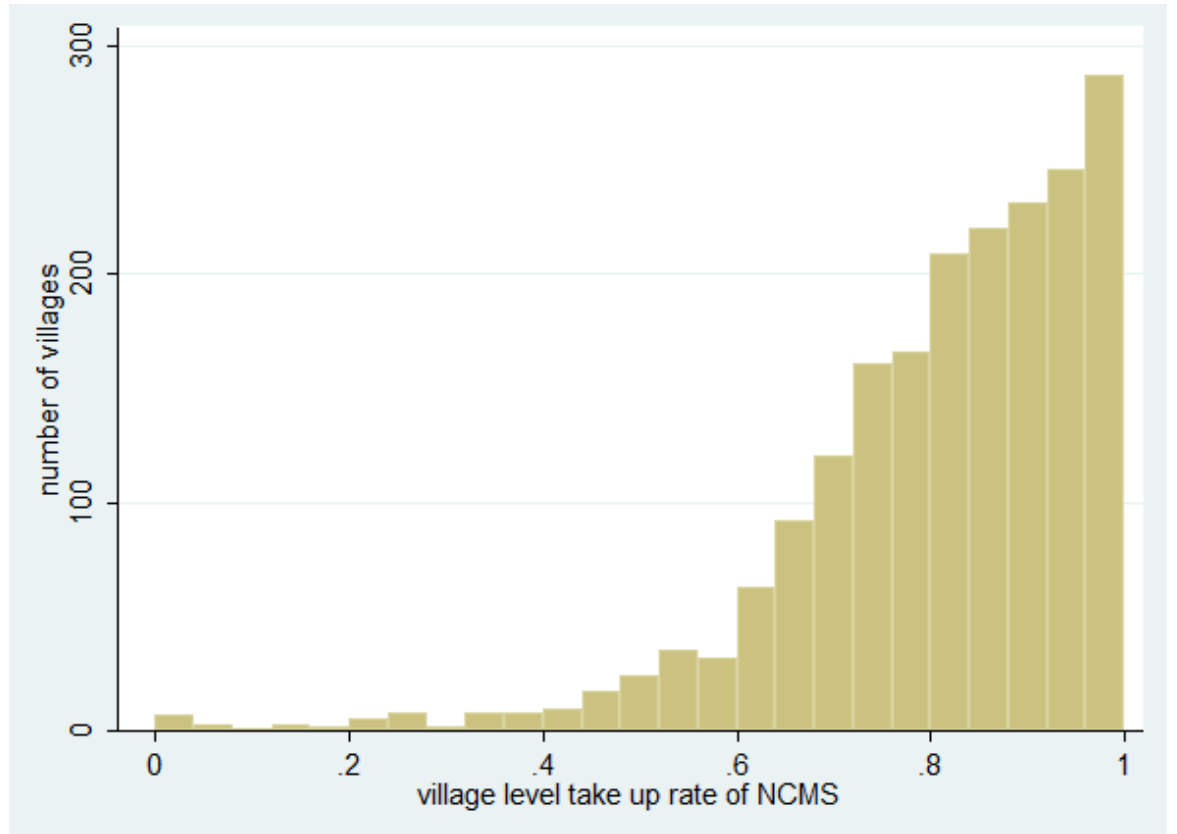

Figure 2: Propensity score distribution of NCMS and non-NCMS counties

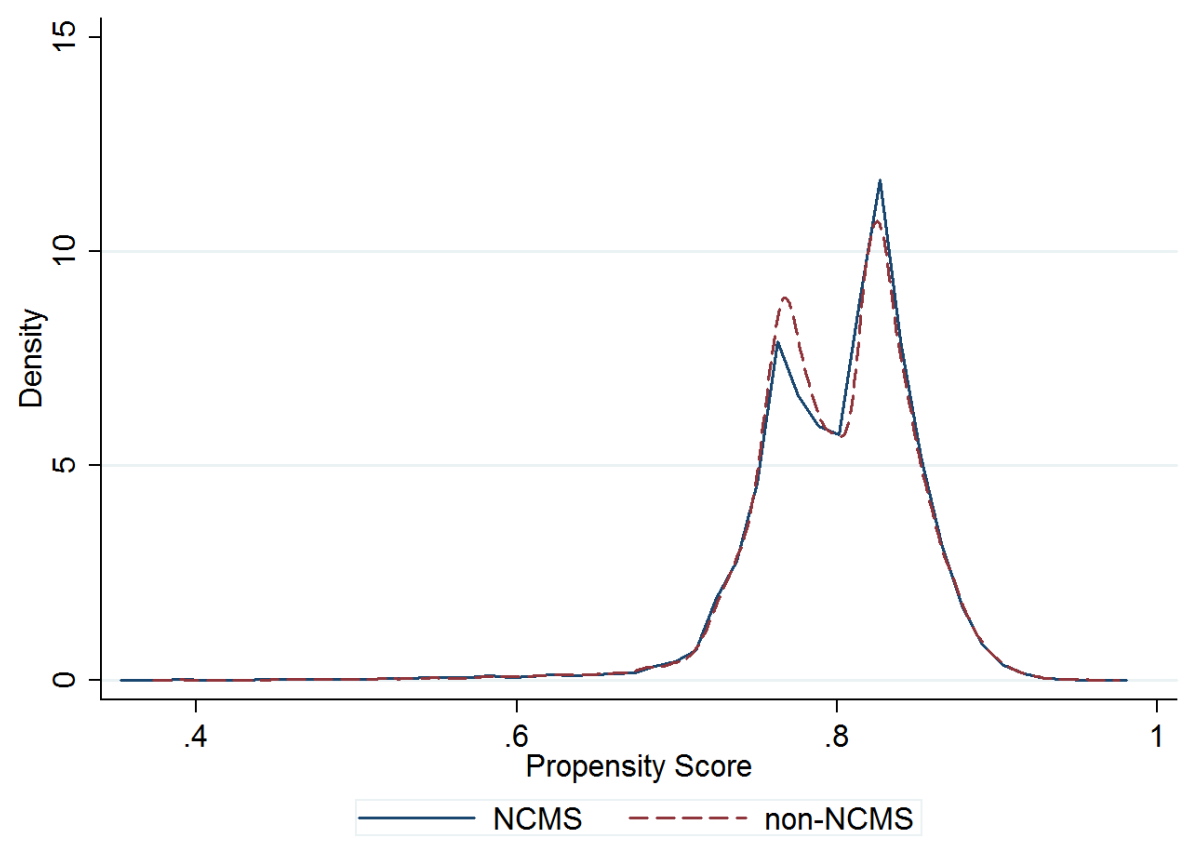


Figure 3: School enrollment rate by NCMS/non-NCMS counties and propensity score bins

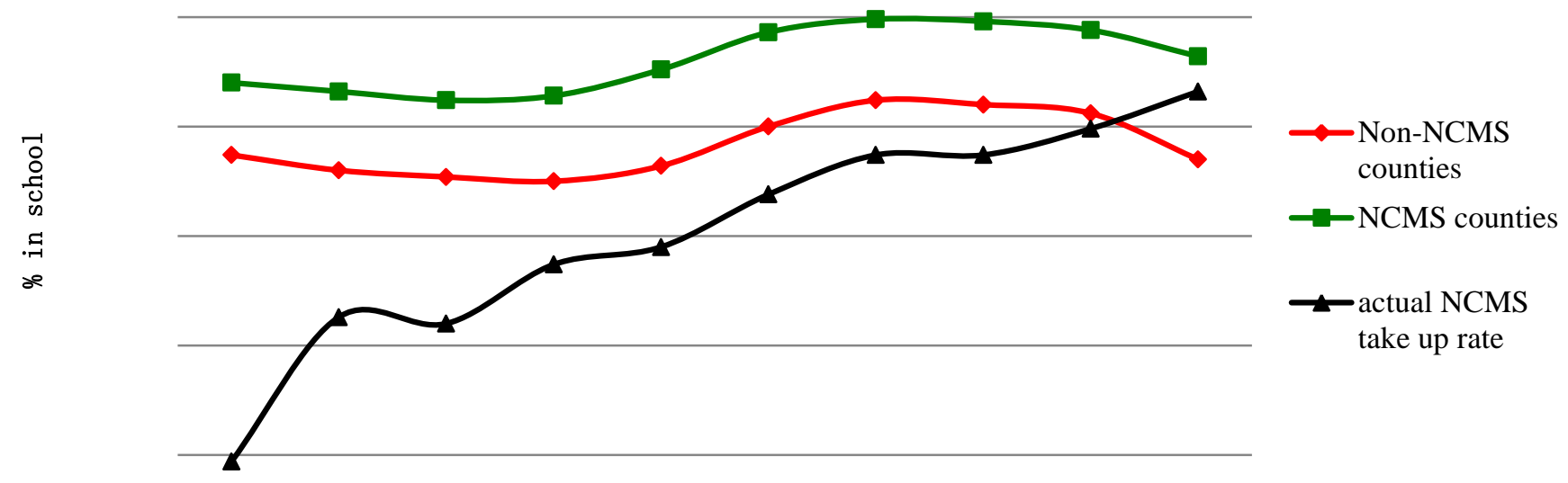

Propensity score bins

Cutoff points for bin definition:

\begin{tabular}{cccc}
\hline & Mean of $\mathrm{p}$ score & Min of $\mathrm{p}$ score & Max of $\mathrm{p}$ score \\
\hline $\operatorname{bin} 1$ & 0.71 & 0.355 & 0.745 \\
$\operatorname{bin} 2$ & 0.755 & 0.745 & 0.762 \\
$\operatorname{bin} 3$ & 0.768 & 0.762 & 0.774 \\
$\operatorname{bin} 4$ & 0.782 & 0.774 & 0.79 \\
$\operatorname{bin} 5$ & 0.798 & 0.79 & 0.806 \\
$\operatorname{bin} 6$ & 0.814 & 0.806 & 0.819 \\
$\operatorname{bin} 7$ & 0.824 & 0.819 & 0.828 \\
$\operatorname{bin} 8$ & 0.833 & 0.828 & 0.839 \\
$\operatorname{bin} 9$ & 0.846 & 0.839 & 0.855 \\
$\operatorname{bin} 10$ & 0.872 & 0.855 & 0.978 \\
\hline
\end{tabular}


Table 1: Summary of village-level mortality of young children and pregnant women, by NCMS status

\begin{tabular}{|c|c|c|c|c|c|c|}
\hline & \multirow{2}{*}{$\begin{array}{c}\text { non- } \\
\text { NCMS } \\
\text { counties }\end{array}$} & \multirow{2}{*}{$\begin{array}{c}\text { All } \\
\text { NCMS } \\
\text { counties }\end{array}$} & \multirow{2}{*}{$\begin{array}{c}\text { County } \\
\text { with } \\
\text { NCMS in } \\
2004\end{array}$} & \multirow{2}{*}{$\begin{array}{c}\text { Counties } \\
\text { with } \\
\text { NCMS in } \\
2006\end{array}$} & \multicolumn{2}{|c|}{ NCMS counties } \\
\hline & & & & & $\begin{array}{l}\text { village take up } \\
\text { rate above } \\
\text { median }(84.1 \%)\end{array}$ & $\begin{array}{l}\text { village take up } \\
\text { rate below } \\
\text { median }(84.1 \%)\end{array}$ \\
\hline $\begin{array}{l}\text { Total \# of } \\
\text { villages }\end{array}$ & 2017 & 1960 & 483 & 1477 & 980 & 980 \\
\hline $\begin{array}{c}\text { \# of young child } \\
\text { deaths }\end{array}$ & $\begin{array}{r}1.10 \\
(1.63) \\
\end{array}$ & $\begin{array}{r}0.77 \\
(1.32) \\
\end{array}$ & $\begin{array}{r}0.93 \\
(1.44) \\
\end{array}$ & $\begin{array}{c}0.72 \\
(1.26) \\
\end{array}$ & $\begin{array}{l}0.754 \\
(1.28) \\
\end{array}$ & $\begin{array}{l}0.788 \\
(1.35) \\
\end{array}$ \\
\hline 0 & $52.65 \%$ & $61.68 \%$ & $55.91 \%$ & $63.57 \%$ & $61.22 \%$ & $62.14 \%$ \\
\hline 1 & $18.69 \%$ & $18.06 \%$ & $19.67 \%$ & $17.54 \%$ & $19.08 \%$ & $17.04 \%$ \\
\hline 2 & $13.09 \%$ & $10.87 \%$ & $12.01 \%$ & $10.49 \%$ & $11.02 \%$ & $10.71 \%$ \\
\hline 3 & $8.28 \%$ & $5.14 \%$ & $5.59 \%$ & $5.34 \%$ & $5.00 \%$ & $5.82 \%$ \\
\hline $3+$ & $7.29 \%$ & $4.25 \%$ & $6.83 \%$ & $3.06 \%$ & $3.67 \%$ & $4.29 \%$ \\
\hline $\begin{array}{l}\text { young child } \\
\text { mortality rate }\end{array}$ & $\begin{array}{c}0.011 \\
(0.016)\end{array}$ & $\begin{array}{l}0.0077 \\
(0.018)\end{array}$ & $\begin{array}{l}0.0094 \\
(0.01)\end{array}$ & $\begin{array}{l}0.0072 \\
(0.024)\end{array}$ & $\begin{array}{l}0.009 \\
(0.02)\end{array}$ & $\begin{array}{l}0.009 \\
(0.04)\end{array}$ \\
\hline $\begin{array}{l}\text { \# of pregnant } \\
\text { women deaths }\end{array}$ & $\begin{array}{c}0.059 \\
(0.296)\end{array}$ & $\begin{array}{c}0.028 \\
(0.167)\end{array}$ & $\begin{array}{c}0.021 \\
(0.143)\end{array}$ & $\begin{array}{c}0.03 \\
(0.174)\end{array}$ & $\begin{array}{c}0.026 \\
(0.158)\end{array}$ & $\begin{array}{c}0.029 \\
(0.175)\end{array}$ \\
\hline 0 & $95.14 \%$ & $97.29 \%$ & $97.83 \%$ & $97.09 \%$ & $97.14 \%$ & $97.45 \%$ \\
\hline 1 & $4.31 \%$ & $2.66 \%$ & $2.07 \%$ & $2.84 \%$ & $2.76 \%$ & $2.55 \%$ \\
\hline 2 & $0.25 \%$ & $0.05 \%$ & $0 \%$ & $0.07 \%$ & $0.10 \%$ & $0 \%$ \\
\hline $2+$ & $0.3 \%$ & $0 \%$ & $0 \%$ & $0 \%$ & $0 \%$ & $0 \%$ \\
\hline $\begin{array}{c}\text { pregnancy } \\
\text { women } \\
\text { mortality rate }\end{array}$ & $\begin{array}{c}0.023 \\
(0.134)\end{array}$ & $\begin{array}{l}0.011 \\
(0.09)\end{array}$ & $\begin{array}{c}0.012 \\
(0.098)\end{array}$ & $\begin{array}{c}0.010 \\
(0.011)\end{array}$ & $\begin{array}{l}0.008 \\
(0.08)\end{array}$ & $\begin{array}{l}0.013 \\
(0.1)\end{array}$ \\
\hline
\end{tabular}

Standard deviation in parentheses. 
Table 2: Summary of school enrollment, by NCMS status

\begin{tabular}{|c|c|c|c|c|c|c|c|c|}
\hline & \multirow{2}{*}{$\begin{array}{l}\text { non- } \\
\text { NCMS } \\
\text { counties }\end{array}$} & \multicolumn{5}{|c|}{ NCMS counties } & \multicolumn{2}{|c|}{ All counties } \\
\hline & & All & $\begin{array}{l}\text { County } \\
\text { with } \\
\text { NCMS in } \\
2004\end{array}$ & $\begin{array}{l}\text { Counties } \\
\text { with } \\
\text { NCMS in } \\
2006\end{array}$ & $\begin{array}{l}\text { not } \\
\text { enrolled } \\
\text { in } \\
\text { NCMS }\end{array}$ & $\begin{array}{l}\text { enrolled } \\
\text { in NCMS }\end{array}$ & male & female \\
\hline $\begin{array}{l}\text { Total \# of school } \\
\text { age children }\end{array}$ & 776,854 & 643,831 & 151901 & 491930 & 128,166 & 515,665 & 763364 & 657334 \\
\hline$\%$ in school all age & $84.13 \%$ & $88.09 \%$ & $86.5 \%$ & $88.5 \%$ & $86.27 \%$ & $88.55 \%$ & $85.4 \%$ & $86.4 \%$ \\
\hline age 6 & $29.28 \%$ & $45.26 \%$ & $36.7 \%$ & $47.9 \%$ & $41.19 \%$ & $46.32 \%$ & $37.5 \%$ & $37.5 \%$ \\
\hline age 7 & $79.97 \%$ & $90.86 \%$ & $86.3 \%$ & $92.3 \%$ & $88.94 \%$ & $91.36 \%$ & $85.8 \%$ & $85.8 \%$ \\
\hline age 8 & $91.74 \%$ & $96.02 \%$ & $94.4 \%$ & $96.5 \%$ & $94.79 \%$ & $96.34 \%$ & $94.2 \%$ & $93.2 \%$ \\
\hline age 9 & $95.14 \%$ & $97.34 \%$ & $96.4 \%$ & $97.6 \%$ & $96.55 \%$ & $97.54 \%$ & $96.4 \%$ & $95.9 \%$ \\
\hline age 10 & $95.58 \%$ & $97.39 \%$ & $96.8 \%$ & $97.6 \%$ & $96.53 \%$ & $97.61 \%$ & $96.7 \%$ & $96 \%$ \\
\hline age 11 & $96.52 \%$ & $97.41 \%$ & $97.2 \%$ & $97.4 \%$ & $96.79 \%$ & $97.56 \%$ & $97.1 \%$ & $96.7 \%$ \\
\hline age 12 & $95.79 \%$ & $97.03 \%$ & $96.5 \%$ & $97.2 \%$ & $95.98 \%$ & $97.30 \%$ & $96.6 \%$ & $96 \%$ \\
\hline age 13 & $95.14 \%$ & $96.58 \%$ & $95.5 \%$ & $96.9 \%$ & $95.65 \%$ & $96.81 \%$ & $96.1 \%$ & $95.4 \%$ \\
\hline age 14 & $91.49 \%$ & $93.39 \%$ & $92.3 \%$ & $93.7 \%$ & $91.22 \%$ & $93.90 \%$ & $92.9 \%$ & $91.7 \%$ \\
\hline age 15 & $85.13 \%$ & $87.52 \%$ & $86.6 \%$ & $87.8 \%$ & $84.91 \%$ & $88.15 \%$ & $86.9 \%$ & $85.7 \%$ \\
\hline age 16 & $68.86 \%$ & $71.60 \%$ & $73.9 \%$ & $70.9 \%$ & $68.10 \%$ & $72.42 \%$ & $70.9 \%$ & $69.4 \%$ \\
\hline
\end{tabular}


Table 3: Across county comparison

\begin{tabular}{|c|c|c|c|c|c|c|c|c|}
\hline County Name & $\mathrm{A}$ & $\mathrm{B}$ & $\mathrm{C}$ & $\mathrm{D}$ & $\mathrm{E}$ & $\mathrm{F}$ & $\mathrm{G}$ & $\mathrm{H}$ \\
\hline Year to first adopt NCMS & 2004 & 2006 & 2006 & 2006 & 2007 & 2007 & 2007 & 2007 \\
\hline Local fiscal income per capita $(2004)^{1}$ & 162 & 166 & 122 & 320 & 141 & 149 & 114 & 68 \\
\hline Fiscal expenditure per capita $(2004)^{1}$ & 493 & 381 & 352 & 660 & 499 & 434 & 366 & 398 \\
\hline Per-capita income $(2004)^{1}$ & 1562 & 1968 & 1503 & 2119 & 1540 & 1515 & 1511 & 1410 \\
\hline \# of children per $\mathrm{HH}^{2}$ & 2.40 & 2.16 & 2.01 & 2.22 & 1.72 & 2.37 & 2.47 & 2.33 \\
\hline \# of adult labor per $\mathrm{HH}^{2}$ & 2.42 & 2.49 & 2.39 & 2.42 & 2.34 & 2.41 & 2.41 & 2.52 \\
\hline Fraction of $\mathrm{HH}$ with migrants ${ }^{2}$ & 0.05 & 0.25 & 0.25 & 0.28 & 0.34 & 0.19 & 0.16 & 0.33 \\
\hline $\log (\text { house value })^{2}$ & 9.44 & 9.70 & 9.55 & 9.67 & 9.79 & 9.64 & 9.44 & 9.65 \\
\hline Contract land ${ }^{2}$ & 3.86 & 2.93 & 3.08 & 2.40 & 3.15 . & 2.35 & 3.37 & 2.84 \\
\hline Fraction of $\mathrm{HH}$ with non-rural hukou ${ }^{2}$ & 0.02 & 0.02 & 0.03 & 0.02 & 0.05 & 0.02 & 0.03 & 0.03 \\
\hline Fraction of $\mathrm{HH}$ with non-local hukou ${ }^{2}$ & 0.03 & 0.03 & 0.05 & 0.02 & 0.10 & 0.02 & 0.03 & 0.03 \\
\hline$\%$ of villages with national poverty status ${ }^{2}$ & 0.59 & 0.66 & 0.37 & 0.60 & 0.44 & 0.65 & 0.65 & 0.47 \\
\hline$\%$ of villages for minority gathering ${ }^{2}$ & 0.33 & 0.38 & 0.35 & 0.44 & 0.20 & 0.45 & 0.31 & 0.13 \\
\hline
\end{tabular}

Note: 1. Source: the 2004 statistical year book of the study, in RMB. 2. Source: the study sample. 
Table 4: Compare households across NCMS participants, NCMS non-participants and non-NCMS counties

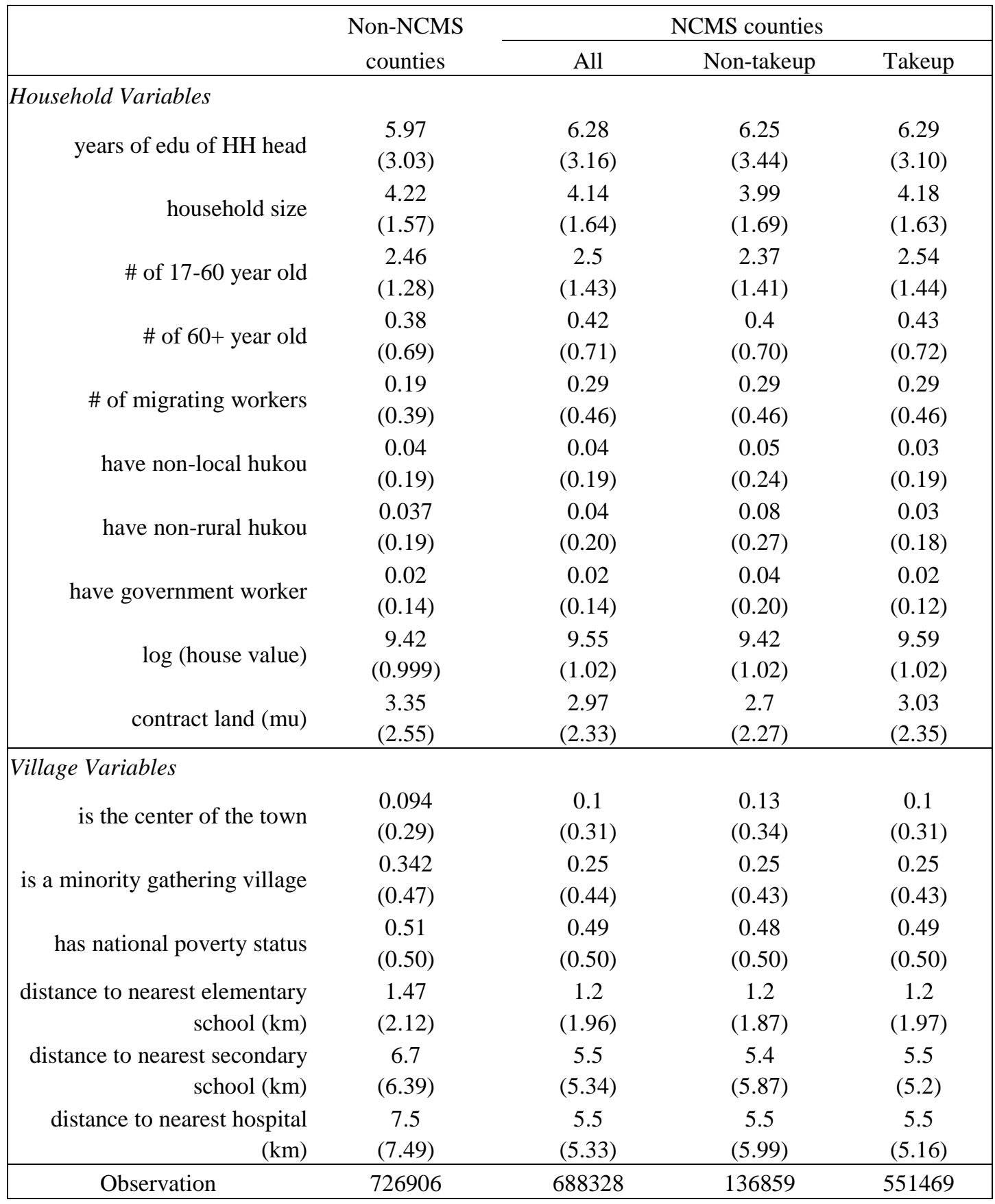


Table 5: regression results of village-level mortality

\begin{tabular}{|l|cc|cc|}
\hline & Any 0-5 year old death & \multicolumn{2}{|c|}{ Any pregnancy death } \\
\hline NCMS offered & -0.087 & & -0.02 & \\
& $(-1.49)$ & & $(-0.91)$ & \\
NCMS take-up rate & 0.012 & -0.031 & 0.003 & -0.003 \\
is the center of the town & $(0.17)$ & $(-0.37)$ & $(0.11)$ & $(-0.12)$ \\
& 0.007 & -0.005 & 0.000 & -0.003 \\
is a minority gathering village & $(0.19)$ & $(-0.16)$ & $(0.000)$ & $(-0.20)$ \\
has national poverty status & -0.034 & 0.038 & 0.005 & 0.01 \\
\# of households in the village & $(1.97)^{*}$ & $(1.63)$ & $(0.76)$ & $(1.04)$ \\
distance to the nearest hospital & 0.023 & 0.004 & -0.006 & -0.008 \\
& $(1.40)$ & $(0.19)$ & $(-0.94)$ & $(-1.22)$ \\
R-square & 0.000 & 0.000 & 0.000 & 0.000 \\
\hline County dummies & $(10.70)^{* *}$ & $(6.72)^{* *}$ & $(4.76)^{* *}$ & $(4.03)^{* *}$ \\
\hline Observations & 0.003 & -0.001 & 0.002 & 0.001 \\
\hline
\end{tabular}

Errors clustered by township.

Robust $t$ statistics in parentheses, ${ }^{*}$ significant at 5\%; ** significant at $1 \%$ 


\begin{tabular}{|c|cccc|}
\hline & $(1)$ & $(2)$ & $(3)$ & $(4)$ \\
& age 6-16 & age 7-15 & age 6-16 & age 7-15 \\
\hline NCMS offered & 0.014 & 0.007 & & \\
& $(4.93)^{* *}$ & $(2.68)^{* *}$ & & \\
NCMS takeup & 0.018 & 0.014 & 0.017 & 0.013 \\
& $(8.36)^{* *}$ & $(6.52)^{* *}$ & $(8.64)^{* *}$ & $(6.78)^{* *}$ \\
\hline counties & All & All & All & All \\
town dummies & NO & NO & YES & YES \\
Observations & 1420685 & 1154614 & 1420685 & 1154614 \\
R-square & 0.28 & 0.05 & 0.29 & 0.06 \\
\hline
\end{tabular}

All regressions control for individual, household and village variables as described in the paper. Error clustered by village. Robust $t$ statistics in parentheses, $*$ significant at $5 \%$; ** significant at $1 \%$,

Table 7: Classical propensity score matching, all using nearest neighbor matching

\begin{tabular}{|c|c|c|c|}
\hline & $\begin{array}{l}\text { Average } \\
\text { treatment } \\
\text { effect }\end{array}$ & std err & t-stat \\
\hline \multicolumn{4}{|l|}{ Panel A: Conditional on 4 NCMS counties } \\
\hline Individual-level School Enrollment & 0.016 & 0.001 & $11.38 * *$ \\
\hline \multicolumn{4}{|l|}{ Panel B: Conditional on all 8 counties } \\
\hline Individual-level school enrollment & 0.026 & 0.001 & $31.11 * *$ \\
\hline \multicolumn{4}{|l|}{ Panel C: Conditional on all 8 Counties } \\
\hline Village level of having any $0-5$ year old death & -0.067 & 0.026 & $-2.63 * *$ \\
\hline Village level young child mortality rate & 0.000 & 0.001 & 0.154 \\
\hline Village level of having any pregnant women death & -0.013 & 0.009 & -1.427 \\
\hline Village-level pregnant women mortality rate & -0.003 & 0.003 & -0.984 \\
\hline
\end{tabular}

$*$ significant at $5 \%$;* significant at $1 \%$. 
Table 8: DID estimates for village-level mortality rate, including all 8 counties

Panel A: Predicted value of village medical insurance participation ratio

\begin{tabular}{|c|ccccc|}
\hline & Number & Mean & Std & Min & Max \\
\hline Non-NCMS & 2017 & 0.8 & 0.053 & 0.357 & 0.995 \\
NCMS & 1960 & 0.8 & 0.055 & 0.355 & 0.989 \\
\hline
\end{tabular}

Panel B: DID estimates

\begin{tabular}{|c|c|c|}
\hline & Children Death & Pregnant Women Death \\
\hline \multirow[t]{2}{*}{ bin 2 (lowest $20-40 \%$ of pscore) } & -0.037 & 0.004 \\
\hline & $(-1.15)$ & $(0.25)$ \\
\hline \multirow[t]{2}{*}{ bin 3} & -0.057 & -0.002 \\
\hline & $(-1.71)$ & $(-0.11)$ \\
\hline \multirow[t]{2}{*}{ bin 4} & -0.033 & -0.018 \\
\hline & $(-0.86)$ & $(-1.08)$ \\
\hline \multirow[t]{2}{*}{ bin 5 (highest $20 \%$ of pscore) } & -0.065 & -0.038 \\
\hline & $(-1.49)$ & $(-2.21)^{*}$ \\
\hline \multirow[t]{2}{*}{ bin $2 *$ NCMSoffered } & -0.016 & -0.012 \\
\hline & $(-0.31)$ & $(-0.53)$ \\
\hline \multirow[t]{2}{*}{ bin $3 *$ NCMSoffered } & -0.047 & -0.027 \\
\hline & $(-0.95)$ & $(-1.35)$ \\
\hline \multirow[t]{2}{*}{ bin $4 * N C M S o f f e r e d$} & -0.034 & -0.004 \\
\hline & $(-0.66)$ & $(-0.17)$ \\
\hline \multirow[t]{2}{*}{ bin $5^{*}$ NCMSoffered } & -0.091 & 0.014 \\
\hline & $(-1.67)$ & $(-0.66)$ \\
\hline NCMSoffered & absorbed & absorbed \\
\hline county dummy & Yes & Yes \\
\hline Observations & 3977 & 3977 \\
\hline R-square & 0.06 & 0.02 \\
\hline
\end{tabular}

Errors clustered by township. Robust t statistics in parentheses, ${ }^{*}$ significant at 5\%; ** significant at $1 \%$. 
Table 9: DID estimates for individual-level school enrollment

\begin{tabular}{|c|c|c|}
\hline & $(1)$ & $(2)$ \\
\hline Sample & All counties & County A vs. non-NCMS counties \\
\hline \multirow[t]{2}{*}{ NCMS offered } & -0.011 & 0.058 \\
\hline & $(2.51)^{*}$ & $(9.49)^{* *}$ \\
\hline \multirow[t]{2}{*}{ bin 2 (lowest $10-20 \%$ of pscore) } & -0.009 & -0.015 \\
\hline & $(3.06)^{* *}$ & $(3.32)^{* *}$ \\
\hline \multirow[t]{2}{*}{ bin 3} & -0.011 & -0.02 \\
\hline & $(3.25)^{* *}$ & $(4.31)^{* *}$ \\
\hline \multirow[t]{2}{*}{ bin 4} & -0.009 & -0.014 \\
\hline & $(2.65)^{* *}$ & $(2.71)^{* *}$ \\
\hline \multirow[t]{2}{*}{ bin 5} & 0.000 & -0.001 \\
\hline & $(0.14)$ & $(-0.34)$ \\
\hline \multirow[t]{2}{*}{ bin 6} & 0.011 & 0.008 \\
\hline & $(3.26)^{* *}$ & $(1.84)$ \\
\hline \multirow[t]{2}{*}{ bin 7} & 0.017 & 0.02 \\
\hline & $(5.21)^{* *}$ & $(4.25)^{* *}$ \\
\hline \multirow[t]{2}{*}{ bin 8} & 0.018 & 0.02 \\
\hline & $(5.22)^{* *}$ & $(4.01)^{* * *}$ \\
\hline \multirow[t]{2}{*}{ bin 9} & 0.022 & 0.027 \\
\hline & $(6.16)^{* *}$ & $(4.98)^{* *}$ \\
\hline \multirow[t]{2}{*}{ bin 10 (highest $10 \%$ of pscore) } & 0.016 & 0.018 \\
\hline & $(3.69)^{* *}$ & $(3.08) * *$ \\
\hline \multirow[t]{2}{*}{ bin $2 *$ NCMS offered } & 0.002 & -0.006 \\
\hline & $(0.600)$ & $(-1.68)$ \\
\hline \multirow[t]{2}{*}{ bin $3 *$ NCMS offered } & 0.003 & -0.002 \\
\hline & $(0.69)$ & $(2.46)^{*}$ \\
\hline \multirow[t]{2}{*}{ bin $4 *$ NCMS offered } & 0.002 & -0.004 \\
\hline & $(0.51)$ & $(-1.52)$ \\
\hline \multirow[t]{2}{*}{ bin $5 *$ NCMS offered } & 0.005 & 0.004 \\
\hline & $(1.33)$ & $(1.87)$ \\
\hline \multirow[t]{2}{*}{ bin $6 *$ NCMS offered } & 0.004 & -0.005 \\
\hline & $(1.09)$ & $(-1.26)$ \\
\hline \multirow[t]{2}{*}{ bin $7 *$ NCMS offered } & 0.003 & 0.003 \\
\hline & $(0.62)$ & $(0.89)$ \\
\hline \multirow[t]{2}{*}{ bin $8 *$ NCMS offered } & 0.003 & -0.001 \\
\hline & $(0.75)$ & $(0.71)$ \\
\hline \multirow[t]{2}{*}{ bin $9 *$ NCMS offered } & 0.003 & 0.002 \\
\hline & $(0.62)$ & $(0.40)$ \\
\hline \multirow[t]{2}{*}{ bin $10 *$ NCMS offered } & 0.006 & -0.004 \\
\hline & $(1.11)$ & $(2.09)^{*}$ \\
\hline county dummies / individual variables & yes / yes & yes / yes \\
\hline Observations & 1420685 & 950681 \\
\hline R-square & 0.27 & 0.29 \\
\hline
\end{tabular}

Error clustered by village. Robust $t$ statistics in parentheses, ${ }^{*}$ significant at $5 \%$; ** significant at $1 \%$. 
Table 10: DID estimators, separating NCMSoffered and NCMStakeup

\begin{tabular}{|c|c|}
\hline & School Enrollment \\
\hline \multirow[t]{2}{*}{ bin $2 *$ NCMS offered } & -0.007 \\
\hline & $(1.32)$ \\
\hline \multirow[t]{2}{*}{ bin $3 *$ NCMS offered } & -0.009 \\
\hline & $(1.23)$ \\
\hline \multirow[t]{2}{*}{ bin $4 *$ NCMS offered } & -0.018 \\
\hline & $(2.24)^{*}$ \\
\hline \multirow[t]{2}{*}{ bin $5 *$ NCMS offered } & -0.008 \\
\hline & $(1.24)$ \\
\hline \multirow[t]{2}{*}{ bin $6 *$ NCMS offered } & -0.007 \\
\hline & $(1.23)$ \\
\hline \multirow[t]{2}{*}{ bin $7 *$ NCMS offered } & -0.007 \\
\hline & $(1.26)$ \\
\hline \multirow[t]{2}{*}{ bin $8 *$ NCMS offered } & -0.003 \\
\hline & $(0.56)$ \\
\hline \multirow[t]{2}{*}{ bin $9 *$ NCMS offered } & -0.009 \\
\hline & $(1.38)$ \\
\hline \multirow[t]{2}{*}{ bin $10 *$ NCMS offered } & -0.011 \\
\hline & $(1.63)$ \\
\hline \multirow[t]{2}{*}{ bin $2 *$ NCMS take-up } & 0.012 \\
\hline & $(2.45)^{*}$ \\
\hline \multirow[t]{2}{*}{ bin $3 *$ NCMS take-up } & 0.015 \\
\hline & $(2.38)^{*}$ \\
\hline \multirow[t]{2}{*}{ bin $4 *$ NCMS take-up } & 0.025 \\
\hline & $(3.48)^{* *}$ \\
\hline \multirow[t]{2}{*}{ bin $5 *$ NCMS take-up } & 0.016 \\
\hline & $(2.81)^{* *}$ \\
\hline \multirow[t]{2}{*}{ bin $6 *$ NCMS take-up } & 0.013 \\
\hline & $(2.63)^{* *}$ \\
\hline \multirow[t]{2}{*}{ bin $7 *$ NCMS take-up } & 0.011 \\
\hline & $(2.19)^{*}$ \\
\hline \multirow[t]{2}{*}{ bin $8 *$ NCMS take-up } & 0.007 \\
\hline & $(1.37)$ \\
\hline \multirow[t]{2}{*}{ bin $9 *$ NCMS take-up } & 0.012 \\
\hline & $(2.29)^{*}$ \\
\hline \multirow[t]{2}{*}{ bin $10 *$ NCMS take- up } & 0.018 \\
\hline & $(3.32)^{* *}$ \\
\hline \multirow[t]{2}{*}{ NCMStakeup } & 0.007 \\
\hline & $(1.93)$ \\
\hline Observations/R-square & $1420685 / 0.27$ \\
\hline
\end{tabular}

Error clustered by village. NCMSoffered is absorbed in the regression. Controls for all bin dummies, county dummies, and individual variables. Robust t statistics in parentheses, ${ }^{*}$ significant at 5\%; ** significant at $1 \%$. 
Table 11: DID estimator on individual-level school enrollment, by child age

\begin{tabular}{|c|c|c|c|c|c|}
\hline & age 6 & age 7 & age 8 & age $9-14$ & age $15-16$ \\
\hline \multirow[t]{2}{*}{ bin $2 *$ NCMS offered } & 0.002 & 0.022 & 0.003 & -0.004 & 0.004 \\
\hline & $(0.14)$ & $(1.97)^{*}$ & $(0.51)$ & (1.1) & $(0.36)$ \\
\hline \multirow[t]{2}{*}{ bin $3 *$ NCMS offered } & 0.009 & 0.009 & -0.003 & -0.001 & 0.006 \\
\hline & $(0.59)$ & $(0.75)$ & $(0.38)$ & $(0.18)$ & $(0.51)$ \\
\hline \multirow[t]{2}{*}{ bin $4 *$ NCMS offered } & 0.004 & 0.012 & 0.006 & 0.002 & 0.000 \\
\hline & $(0.23)$ & $(0.97)$ & $(0.76)$ & $(0.42)$ & $(0.03)$ \\
\hline \multirow[t]{2}{*}{ bin $5 *$ NCMS offered } & 0.028 & 0.021 & 0.002 & 0.002 & 0.001 \\
\hline & (1.87) & $(1.71)$ & $(0.27)$ & $(0.60)$ & $(0.08)$ \\
\hline \multirow[t]{2}{*}{ bin $6 *$ NCMS offered } & 0.029 & 0.005 & 0.000 & -0.002 & 0.015 \\
\hline & (1.68) & $(0.41)$ & $(0.01)$ & $(-0.49)$ & $(1.44)$ \\
\hline \multirow[t]{2}{*}{ bin $7 *$ NCMS offered } & 0.038 & 0.007 & 0.007 & -0.006 & 0.007 \\
\hline & $(2.22)^{*}$ & $(0.59)$ & $(0.97)$ & $(-1.86)$ & $(0.65)$ \\
\hline \multirow[t]{2}{*}{ bin $8 *$ NCMS offered } & 0.029 & 0.017 & 0.009 & -0.002 & 0.006 \\
\hline & (1.68) & $(1.34)$ & $(1.29)$ & $(-0.57)$ & $(0.60)$ \\
\hline \multirow[t]{2}{*}{ bin $9 *$ NCMS offered } & 0.041 & 0.009 & -0.006 & -0.002 & 0.013 \\
\hline & $(2.43)^{*}$ & $(0.70)$ & $(0.82)$ & $(0.70)$ & (1.18) \\
\hline \multirow[t]{2}{*}{ bin $10 *$ NCMS offered } & 0.038 & 0.006 & 0.004 & -0.003 & 0.006 \\
\hline & $(2.14)^{*}$ & $(0.44)$ & $(0.42)$ & $(0.75)$ & $(0.50)$ \\
\hline NCMS offered & absorbed & absorbed & absorbed & absorbed & absorbed \\
\hline bin $2-$ bin 10 dummies & Yes & Yes & Yes & Yes & Yes \\
\hline County dummies & Yes & Yes & Yes & Yes & Yes \\
\hline Individual variables & Yes & Yes & Yes & Yes & Yes \\
\hline Observations & 192999 & 184504 & 191658 & 768766 & 236244 \\
\hline $\mathrm{R}$-square & 0.11 & 0.07 & 0.03 & 0.02 & 0.05 \\
\hline
\end{tabular}

Error clustered by village. Robust t statistics in parentheses,* significant at 5\%; ** significant at $1 \%$. 
Table 12: DID estimator on individual-level school enrollment, by \% of household members being 17-60 year old (adult labor)

\begin{tabular}{|c|c|c|c|c|}
\hline & $\begin{array}{c}\% \text { of adult labor } \\
1^{\text {st }} \text { quartile }\end{array}$ & $\begin{array}{c}\% \text { of adult labor } \\
2^{\text {nd }} \text { quartile }\end{array}$ & $\begin{array}{c}\% \text { of adult labor } \\
3^{\text {rd }} \text { quartile }\end{array}$ & $\begin{array}{c}\% \text { of adult labor } \\
4^{\text {th }} \text { quartile }\end{array}$ \\
\hline \multirow[t]{2}{*}{ bin $2 *$ NCMS offered } & 0.002 & 0.002 & 0.006 & -0.001 \\
\hline & $(0.28)$ & $(0.42)$ & $(1.15)$ & $(-0.11)$ \\
\hline \multirow[t]{2}{*}{ bin $3 *$ NCMS offered } & -0.006 & 0.007 & 0.015 & 0.001 \\
\hline & $(-0.84)$ & $(1.22)$ & $(2.67)^{* *}$ & $(0.12)$ \\
\hline \multirow[t]{2}{*}{ bin $4 *$ NCMS offered } & -0.001 & 0.008 & 0.008 & 0.004 \\
\hline & $(-0.16)$ & $(1.24)$ & $(1.35)$ & $(0.56)$ \\
\hline \multirow[t]{2}{*}{ bin $5 *$ NCMS offered } & -0.002 & 0.01 & 0.018 & 0.000 \\
\hline & $(-0.39)$ & (1.70) & $(3.19)^{* *}$ & $(0.05)$ \\
\hline \multirow[t]{2}{*}{ bin $6 *$ NCMS offered } & 0.002 & -0.003 & 0.009 & 0.015 \\
\hline & $(0.34)$ & $(-0.47)$ & (1.70) & $(1.99) *$ \\
\hline \multirow[t]{2}{*}{ bin $7 *$ NCMS offered } & -0.003 & 0.003 & 0.004 & 0.008 \\
\hline & $(-0.43)$ & $(0.57)$ & $(0.70)$ & $(1.04)$ \\
\hline \multirow[t]{2}{*}{ bin $8 *$ NCMS offered } & 0.001 & 0.004 & 0.012 & -0.002 \\
\hline & $(0.22)$ & $(0.68)$ & $(2.21)^{*}$ & $(-0.31)$ \\
\hline \multirow[t]{2}{*}{ bin $9 *$ NCMS offered } & 0.003 & 0.004 & 0.006 & 0.005 \\
\hline & $(0.52)$ & $(0.66)$ & (1.00) & $(0.80)$ \\
\hline \multirow[t]{2}{*}{ bin $10 *$ NCMS offered } & 0.005 & 0.017 & 0.014 & 0.008 \\
\hline & $(0.78)$ & $(2.16)^{*}$ & $(2.29)^{*}$ & $(1.23)$ \\
\hline NCMS offered & absorbed & absorbed & absorbed & absorbed \\
\hline bin $2-$ bin 10 dummies & Yes & Yes & Yes & Yes \\
\hline County dummies & Yes & Yes & Yes & Yes \\
\hline Individual variables & Yes & Yes & Yes & Yes \\
\hline Observations & 364480 & 380721 & 376187 & 299297 \\
\hline $\mathrm{R}$-square & 0.32 & 0.33 & 0.28 & 0.18 \\
\hline
\end{tabular}

Error clustered by village. Robust $t$ statistics in parentheses, ${ }^{*}$ significant at $5 \%$; ** significant at $1 \%$. 